\title{
PAISAJE MONUMENTAL Y COMPLEIIDAD SOCIAL EN LOS PESCADORES ARCAICOS DE LA COSTA DE ARICA: ANÁLISIS DE MATERIALIDAD Y ARTE PICTÓRICO EN LA CUEVA LA CAPILLA
}

\section{MONUMENTAL LANDSCAPE AND SOCIAL COMPLEXITY AMONG THE ARCHAIC FISHERMEN OF THE ARICA COAST: AN ANALYSIS OF THE MATERIALITY AND PICTORIAL ART AT LA CAPILLA CAVE}

\author{
IVÁN MUÑ̃z Ovalle*
}

\begin{abstract}
El artículo tiene como objetivo analizar las evidencias culturales halladas en la cueva La Capilla, con el propósito de conocer la interacción social que se dio en su interior. Planteamos este objetivo dentro del marco de la arqueología social, considerando que es un sitio único en la costa del norte de Chile, donde hemos encontrado evidencias pictóricas y restos culturales en un entorno paisajístico relacionado con poblaciones de pescadores correspondientes al Período Arcaico Tardío (1800-800 AC). La discusión gira en torno a la importancia de la cueva, la que al parecer fue erigida por los pescadores como un monumento de múltiples funciones sociales.
\end{abstract}

Palabras clave: paisaje, monumento, interacción social

The article analyzes cultural evidence found at La Capilla cave to learn about the social interactions that occurred there. The analysis is undertaken from the lens of social archaeology, taking into account that the site is a unique place in Chile's northern coast. The site yielded pictorial evidence and cultural remains in an environment associated with fishing settlements of the Late Archaic Period (1800-800 BC). The discussion revolves around the importance of the cave, which seems to have been built by fishermen as a monument with a variety of social functions.

Key words: landscape, monument, social interaction

\section{INTRODUCCIÓN}

En la costa del extremo norte de Chile, en el transcurso del segundo milenio antes de Cristo, se aprecia una serie de innovaciones en el contexto de las estructuras organizacionales de los pescadores asentados en el litoral (Muñoz 1982) (Tabla 1). El hallazgo de nuevas tecnologías nos permite realizar estas observaciones, junto a determinados cambios en los patrones habitacionales y de entierro. Así, por ejemplo, los campamentos mantienen el esquema de organizarse en un espacio abierto, donde se desarrollaba la confección de tecnologías, y un espacio cerrado tipo morada, que les servía para cobijarse. En Arica hemos definido dos tipos de campamentos, los que se diferencian por las actividades que desarrollaron. En la franja costera, sector Quiani y Morro, se han encontrado campamentos de función más permanente, entre cuyas características está la accesibilidad a los recursos marinos; además, en ellos hallamos actividades de mantenimiento. Distinto es el caso de los campamentos ubicados en la confluencia del valle de Azapa con la quebrada de Acha, los que fueron levantados con el propósito de desarrollar actividades como la recolección de frutos, raíces y madera, y la caza menor (Muñoz \& Arriaza 2006).

Respecto de las tecnologías, si bien la fibra vegetal constituye la materia prima utilizada con mayor frecuencia en la confección de vestimentas, utensilios domésticos e

* Iván Muñoz Ovalle, Universidad de Tarapacá, casilla 6d, Arica, Chile, email: imunoz@uta.cl 
Tabla 1. Secuencia cultural, valle de Azapa y costa de Arica Table 1. Cultural sequence, Azapa Valley and Arica coast.

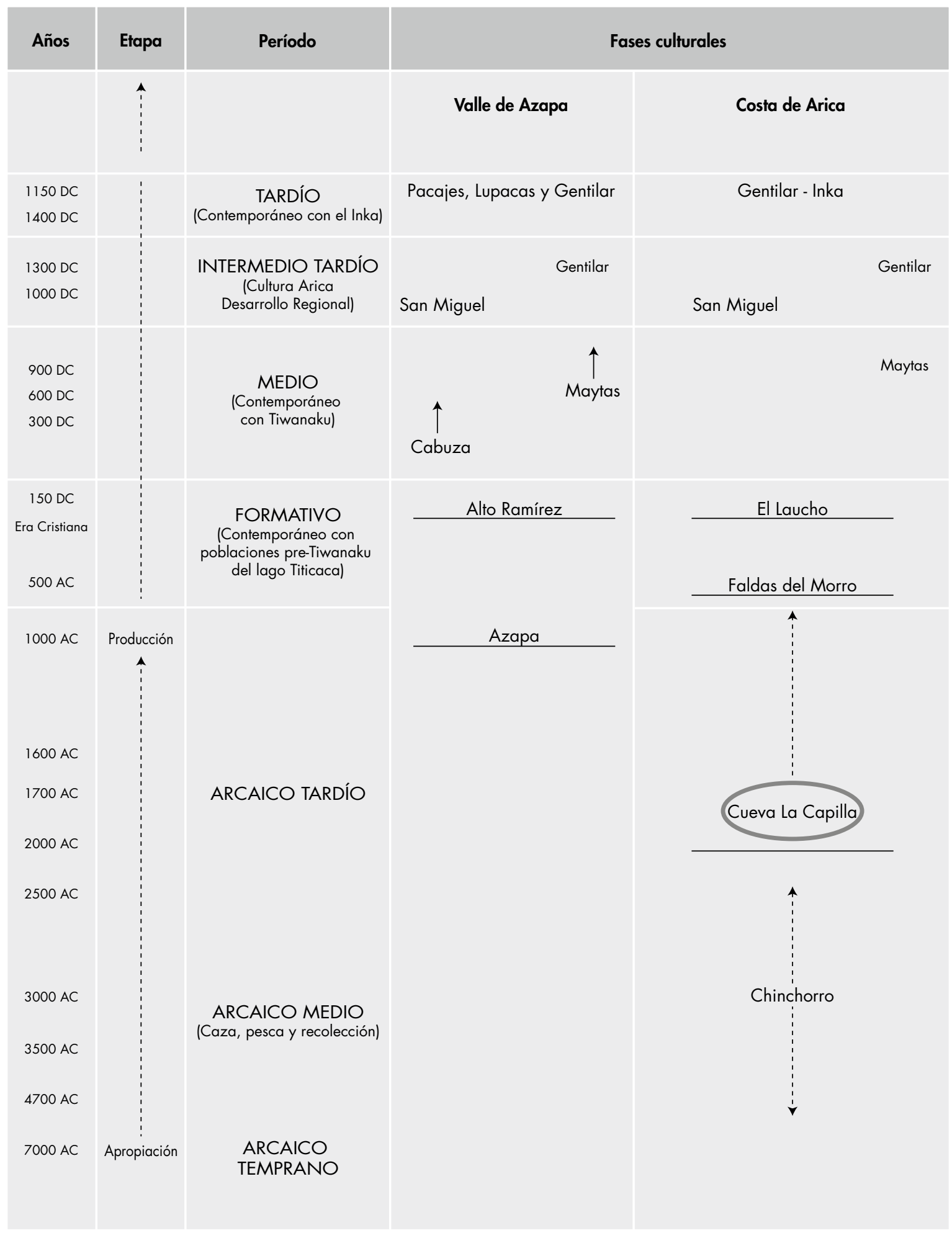


instrumentos de trabajo, observamos una mayor diversidad e incremento de objetos culturales. Estos corresponden a piezas de cestería, vestimenta y artefactos domésticos confeccionados en fibra vegetal, lana y algodón. Algunas de estas piezas presentan motivos decorados con formas geométricas, zoo y antropomorfas, pintadas de colores rojo y negro. Sin embargo, como consecuencia de la intensificación de los recursos pecuarios en la costa, en el último milenio después de Cristo se observa un reemplazo paulatino en el uso de algodón y fibra vegetal por la fibra animal (Muñoz 1989).

Existen otras tecnologías que formaron parte del incremento del acervo cultural de los pescadores arcaicos. Una de ellas es la metalurgia, cuyas primeras piezas corresponden a figuras con formas serpenteadas, cucharas, diadema, alfileres y láminas de forma circular. También el uso del pirograbado en las calabazas aparece como un elemento diagnóstico en esta etapa, igual que las sustancias psicotrópicas evidenciadas en el complejo alucinógeno, compuesto por cajitas, tabletas, espátulas, brochas y tubos. El uso de estos implementos en la costa pudo haber sido consecuencia de la convivencia temporal entre pescadores que se habían asentado en el valle de Azapa con el propósito de practicar una horticultura de carácter familiar, basada en tubérculos y cucurbitáceas (Santoro 1980a, 1980b; Muñoz 1982).

El turbante es otro indicador de la presencia de nuevos rasgos en el contexto de los pescadores arcaicos. Inicialmente se caracterizan por varias cuerdas de hilados de lana, adornados con cuentas calcáreas (Dauelsberg 1974). Sin embargo, a partir del 1000 AC esta pieza se confecciona mediante diversas fajas de hilados y con variados adornos, como alfileres de formas serpenteadas, elaborados en cobre. Otro objeto de carácter ceremonial que aparece por primera vez entre los pescadores es el tocado, hecho con plumas de aves tropicales, puesto a manera de adorno en la frente del difunto (Focacci 1974; Rivera et al. 1974).

Durante este mismo período la momificación artificial practicada a los cuerpos de los difuntos -uno de los rasgos más característicos de los pescadores arcaicos- comienza a desaparecer, quedando solamente algunos rasgos culturales asociados a los ritos mortuorios Chinchorro, como las mascarillas de barro y la decoración geométrica en algunos objetos puestos como ofrenda. Para esta época, los estudios realizados en el cementerio Quiani 7 señalan la aparición de entierros de cuerpos con las piernas flexionadas, decúbito dorsal o lateral, sin momificación artificial, que constituyen el primer antecedente para discutir los cambios o las transformaciones que sufrieron estas poblaciones costeras en el patrón mortuorio (Dauelsberg 1974).
Junto a estos cambios, uno de los aspectos más sobresalientes de este período de transición es el establecimiento de espacios ceremoniales/rituales como áreas separadas de los sitios de campamento. La cueva La Capilla es uno de los ejemplos más relevantes de este nuevo orden social. Los estudios realizados en la década de los ochenta -y retomados durante la primera década del 2000- registraron la presencia de un gran número de faldellines, enterrados intencionalmente bajo el piso ocupacional de la cueva (Muñoz \& Chacama 1982). Por la forma en que fueron dispuestos y al no presentar evidencias de uso, Muñoz y Chacama (1982) y luego Chacama y Muñoz (1991) propusieron que estas prendas habrían sido parte de un ceremonial relacionado con los ciclos vitales en las poblaciones de pescadores. Esta hipótesis se sustenta en la información descrita por Murra (1975), que señala las distintas etapas que los jóvenes cusqueños de linaje real debían atravesar, por el rito de paso, con cambios de vestimenta, para convertirse en adultos. Estos antecedentes etnográficos reforzarían la hipótesis de que en la cueva se habrían efectuado rituales de iniciación a la adultez. Chacama y Muñoz (1991) plantean que estos rituales fueron fruto del desarrollo "espiritual" de grupos precedentes, que habrían estructurado un esquema ideológico-social que se manifiesta en la denominada Cultura Chinchorro, 5000-2000 AC (Bittman \& Munizaga 1976), y que se fue desarrollando en el tiempo hasta llegar a los grupos de pescadores que habitaron la cueva La Capilla. Estos ya habían definido espacios específicos para complejos ceremoniales, integrando una serie de símbolos ideográficos relacionados con la vida ceremonial de los pescadores, los que estarían representados en las numerosas pictografías que hoy hallamos en dicha cueva.

En el presente artículo analizaremos la ocupación de la cueva, que fue escenario de múltiples actividades sociales durante el período de transición Arcaico-Formativo, con el fin de profundizar en la organización social de los pescadores tempranos que habitaron la costa de Arica entre 1700 y 800 AC.

\section{BREVE COMENTARIO SOBRE LA ARQUEOLOGIA DEL PAISAJE}

Desde el punto de vista teórico, el paisaje constituye el eje central sobre el que se asienta la discusión de la monumentalidad y, según Clarke (1977), el que mantiene como elemento fundamental la dimensión social. Para Criado (1993), esta dimensión social es una construcción dinámica enraizada en la cultura. Anschuetz (2001), en tanto, plantea que los estudios sobre arqueología del 
paisaje permiten apreciar los aspectos geográficos como una entidad activa y compleja en relación con las vidas humanas, por lo que, dentro de los enfoques culturales del paisaje, estos pueden ser investigados para entender las formas en que se exponen y reproducen las identidades culturales. Zedeño (1997), por su parte, señala que el paisaje se vuelve significativo mediante mitos, relatos, memorias y tradiciones orales. La identidad de los ancestros es evocada localizando lugares y llevando a cabo eventos y actividades en el paisaje.

Según López Austin (1980), para las sociedades indígenas mesoamericanas las cuevas constituyen la entrada a las entrañas de la tierra sumergida en el agua y, así, se les considera lugares de origen vinculados con los ancestros, constituyéndose en la estructura basal de origen mítico sobre la que se legitimizan los grupos étnicos. Igual que las cuevas, en los Andes los cerros y las montañas constituyen la deidad fundacional mítica de los pueblos, por lo tanto, cada pueblo tiene una montaña como elemento protector identitario, demostrando la estrecha relación del hombre con su entorno (Rivière 1982).

Por la ubicación y características físicas de la cueva La Capilla, las estrategias de monumentalización y exhibición son las que mejor se acomodan para su estudio. Su ubicación a media ladera contribuye a que se produzca una alteración espacial del entorno, la que habría potenciado una mayor visibilidad del paisaje costero. Pensamos que la importancia que pudo haber alcanzado la cueva en el contexto de la percepción y el reordenamiento de los mapas mentales de los pescadores arcaicos de Arica, habría tenido su base en la imponente estructura granítica y galerías que la conforman, constituyéndose en una estructura que le dio identidad a los pescadores del litoral ariqueño.

\section{LA CUEVA: OCUPACIÓN DEL RECINTO, EXCAVACIÓN Y DATACIONES}

El sitio La Capilla 1 se encuentra ubicado en la base de un abrupto acantilado de 700 metros de altura, perteneciente a las estribaciones de la cordillera de la Costa (fig. 1). La cueva en que se encuentra el sitio arqueológico corresponde a una formación de sedimentos marinos con concreciones de cal (Muñoz, J. 1973) (figs. 2 y 3). Se ubica a menos de 50 metros del mar, por lo tanto proporciona una buena accesibilidad a los recursos costeros. La boca de la cueva está orientada al mar, dirección noroeste, y se ensancha en galerías perpendiculares a la entrada dándole a la cueva una forma de T. Tiene 21 metros de profundidad y una pendiente de $22^{\circ}$, desde el umbral hasta el fondo. La pendiente de entrada está interrumpida a consecuencia de un desprendimiento de rocas de la bóveda de la cueva, con lo que se ha formado un pircado natural (fig. 4, perfil en corte A-A).

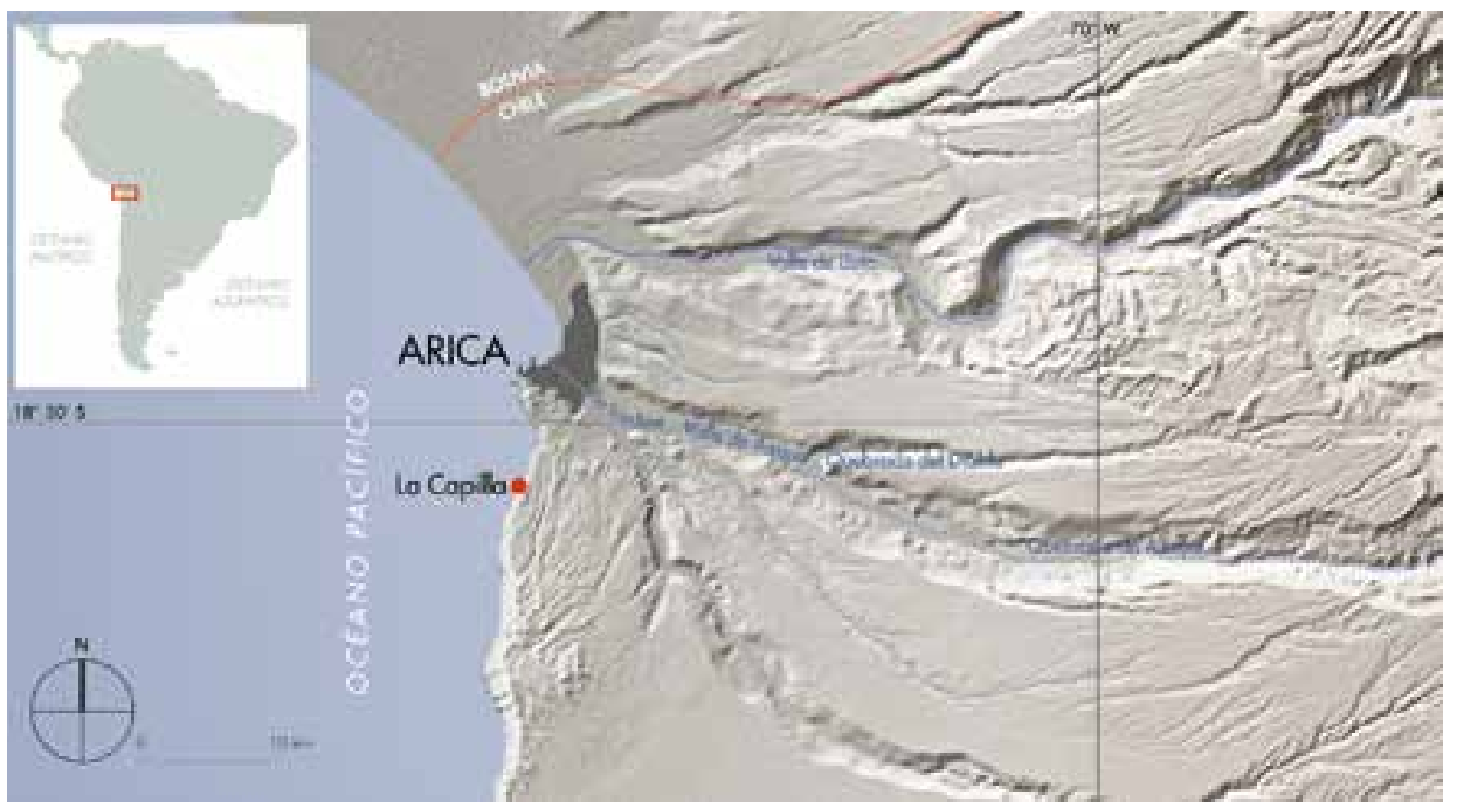

Figura 1. Cartografía sección de Arica y valle de Azapa (XV Región Arica y Parinacota, Chile).

Figure 1. Map of Arica-Azapa Valley area (Region XV, Arica and Parinacota, Chile). 


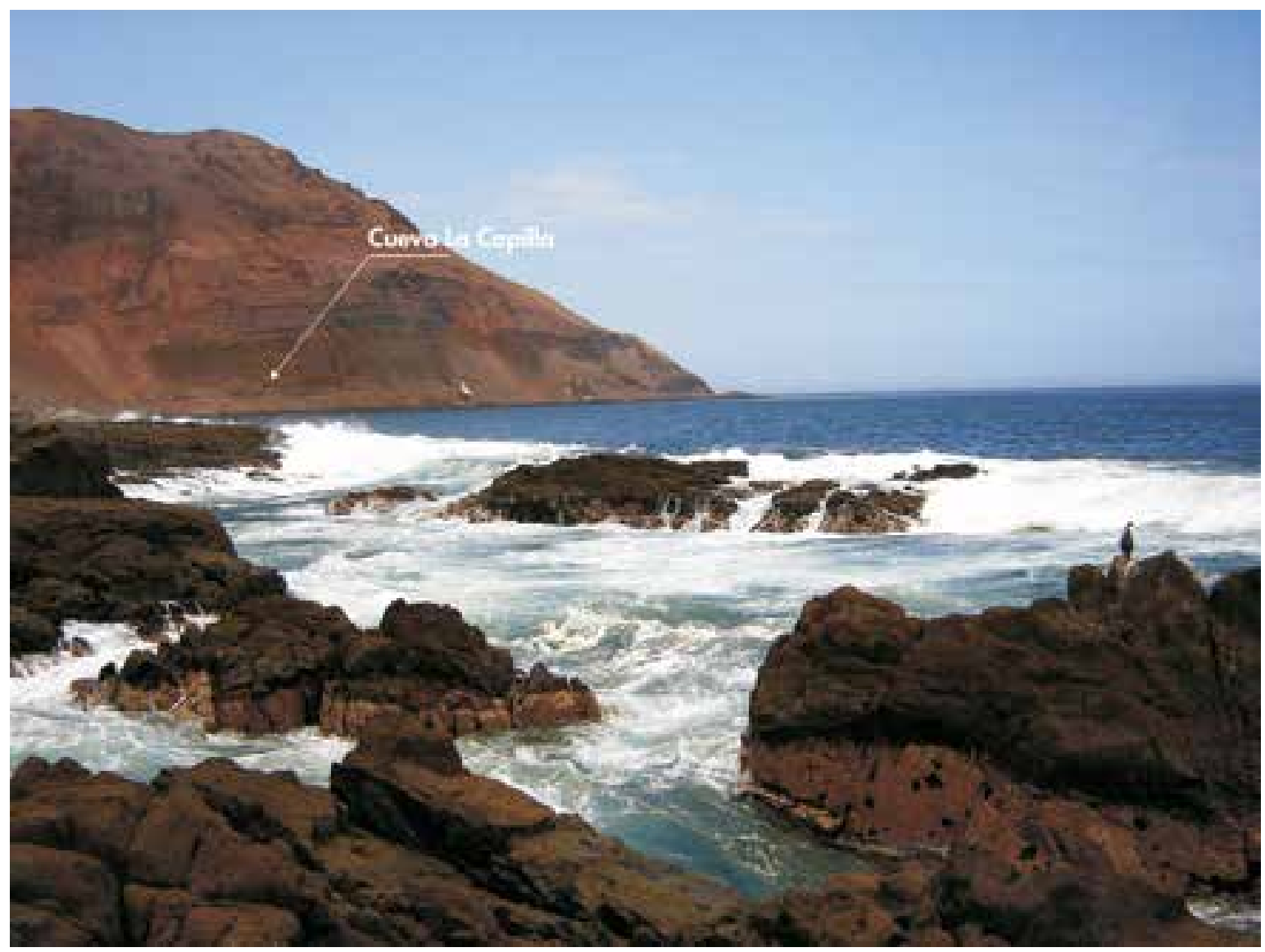

Figura 2. Entorno cueva La Capilla.

Figure 2. Location of La Capilla cave and its environs.

Es en este sector, frente al acceso, donde se planificó la excavación. Las pictografías se hallan en la pared de fondo (panel 2) y en una de las paredes laterales (panel 1), hasta donde en ambos casos llega la luz solar.

El estudio fue realizado en dos etapas: la primera, cuando se excavó la cueva en la década de los ochenta, y la segunda, cuando realizamos una detallada prospección del paisaje a mediados del año 2000, analizando aspectos como la visualización, el tránsito y la permeabilidad del entorno de la cueva.

Respecto de la excavación, primero se realizaron dos pozos de sondeo para medir la extensión del sitio. Esto proporcionó un antecedente interesante, pues el radio de ocupación de la cueva está asociado directamente a la luz solar que le llega. Las pinturas fueron hechas utilizando dicha luz, ya que desaparecen en los sectores donde hay ausencia de esta. Para efectuar los trabajos de excavación se ubicó el tramo más bajo de la pendiente, en él se trazó una trinchera de $10 \mathrm{~m}$ de largo por uno de ancho, dividiéndose en cuadrículas de $1 \mathrm{~m}^{2}$ (fig. 4). Por lo complejo de la conservación de la estratigrafía, la

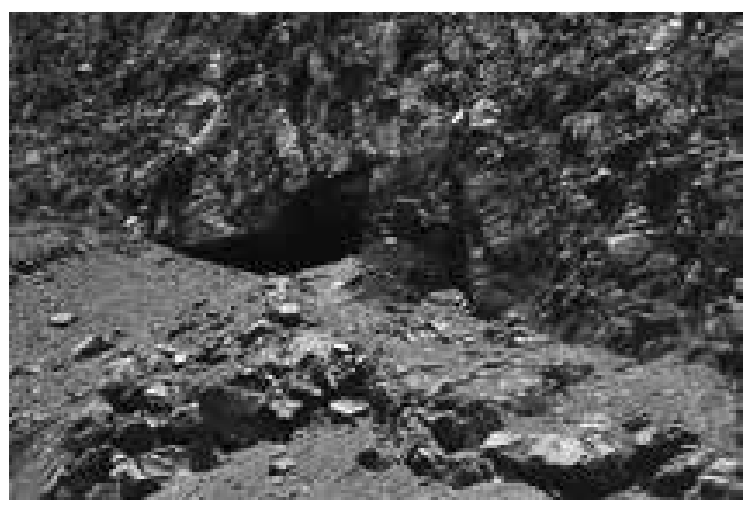

Figura 3. Acceso a cueva La Capilla.

Figure 3. Entrance to La Capilla cave.

excavación se planteó desde la pendiente más alta hacia los niveles inferiores, para así exponer un perfil amplio que permitiese constatar la uniformidad de los estratos excavados y controlar sistemáticamente los hallazgos.

La selección del material se hizo mediante sistemas de harneo con malla de $1 \mathrm{~cm}$ de diámetro, luego se 

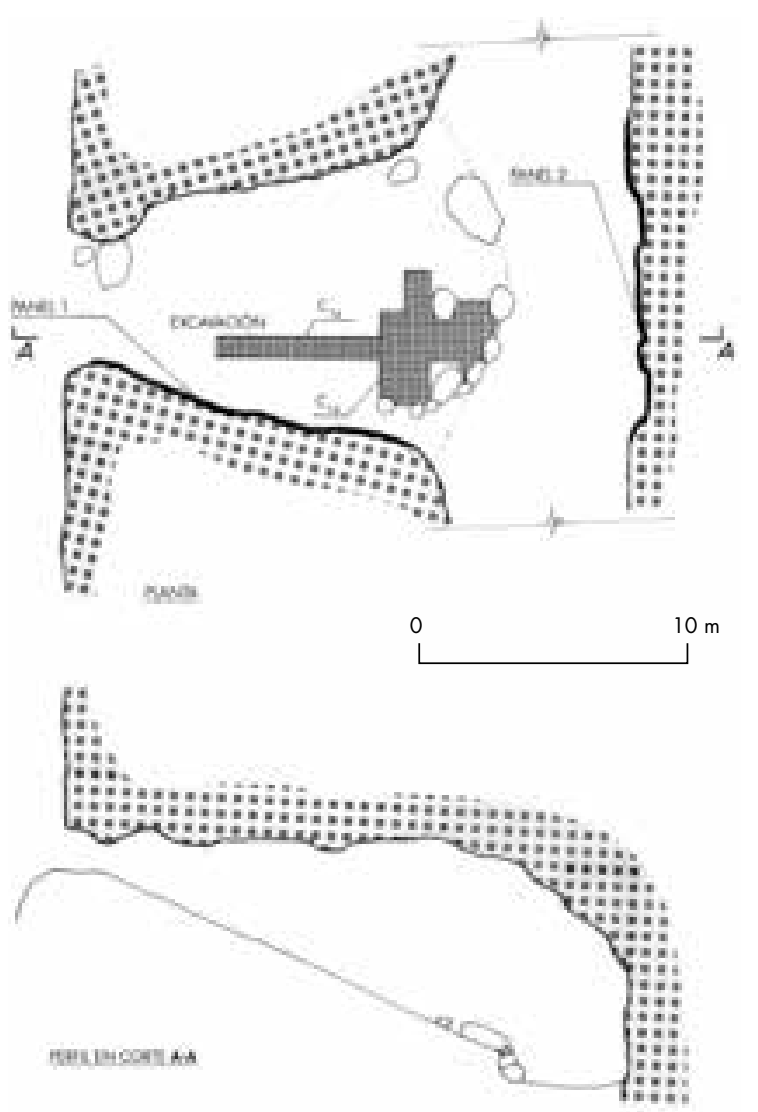

2

Figura 4. Planta y perfil, excavación cueva La Capilla.

Figure 4. Layout and profile of the excavation at La Capilla cave.

procedió a la separación del material arqueológico para su posterior clasificación. El criterio utilizado para determinar los estratos naturales -y así el trabajo de excavación- consistió en tomar en cuenta la calidad del estrato en cuanto a su textura, considerando tipos de componentes (arena, gravilla, clastos, etc.) y grado de compactación. El color de los estratos no fue muy significativo, ya que puede tener diversas coloraciones producto de algún tipo de descomposición orgánica o alguna otra circunstancia (fig. 5).

\section{Estrato 1}

Superficial. Se caracteriza por una pequeña capa de material suelto de aproximadamente $5 \mathrm{~cm}$ de espesor. Está compuesto por pequeños clastos y arena terrosa de grano grueso. Presenta fragmentos de vidrios, envoltorios y colillas de cigarrillos y cuescos de duraznos, entre otras evidencias.

\section{Estratos 2 y 3}

Culturalmente estériles, gran cantidad de pequeños clastos angulosos, mezclados con un suelo de gravilla y arena gruesa. Estos clastos corresponden a restos de roca y en el estrato 2 su espesor máximo es de $5 \mathrm{~cm}$. Ambos estratos son bastante uniformes, lo que constituye un sello natural puesto sobre el depósito cultural en cuestión. La diferencia entre ambos es que en el estrato 3 existe una mayor predominancia de los clastos mencionados, los que alcanzan un espesor promedio de $15 \mathrm{~cm}$.

\section{Estrato 4}

Constituye el estrato ocupacional de la cueva. Presenta un espesor de $6 \mathrm{a} 7 \mathrm{~cm}$, un color de tonalidad amarillenta y está constituido por restos orgánicos, principalmente fibras vegetales, conchas y vértebras de pescado. Además, se hallaron restos de osamentas humanas, como dos iliones (huesos de la cadera) correspondientes a un niño de 6 a 9 años y un individuo joven de sexo masculino de 17 a 20 años (fig. 6). Recientemente, como consecuencia de las excavaciones llevadas a cabo por Marcela Sepúlveda, Verónica Silva (comunicación personal) ha identificado el cuerpo de un recién nacido en posición decúbito lateral, flectado, y varios huesos o dientes que corresponden a un número mínimo de cinco individuos: dos menores de un año, dos juveniles entre 12 y 18 años y un adulto joven.

De este estrato fueron obtenidos tres fechados radiocarbónicos. La primera fecha corresponde a la parte superior del estrato, en cambio las dos restantes corresponden a la base del estrato. Un aspecto particular de este estrato es la ausencia de fogones en sus depósitos (ver Tabla 2).

\section{Estrato 5}

Está constituida por arena fina de playa de color gris, la que se encuentra bastante limpia, sin contaminación de restos orgánicos. Este es el piso con el que se encontraron los primeros ocupantes de la cueva, aunque no hay evidencias culturales. Sin embargo, en los primeros centímetros que corresponden al nivel superior se hallan restos orgánicos que son consecuencia del contacto con el estrato superior 4. En este estrato fueron hallados 23 faldellines sin uso, doblados. No se pudo obtener la profundidad total del estrato 5 , aunque en los sectores donde fueron hallados los faldellines la profundidad alcanzó más de $30 \mathrm{~cm}$. 

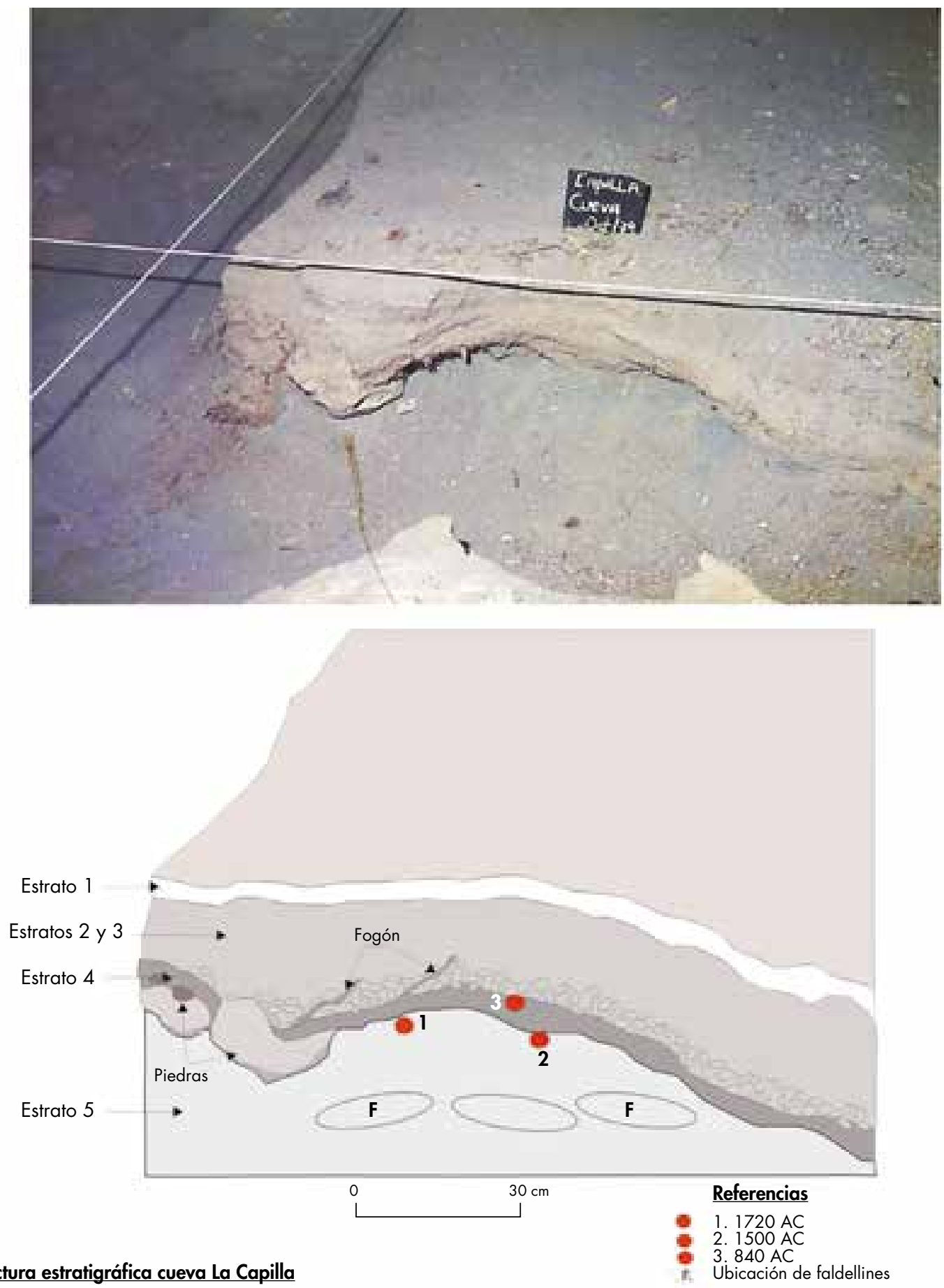

\section{Lectura estratigráfica cueva La Capilla}

Estrato $N^{0}$ 1. Superficial. Composición de arena. Evidencias de desechos modernos: envoltorios y colillas de cigarrillos, vidrios y cuescos de duraznos.

Estratos $N^{\circ} 2$ y 3. Composición de arena, clastos y gravilla. Ausencia de evidencias culturales. Lentes de fogones que ascienden desde nivel superior del estrato $\mathrm{N}^{\circ} 4$. Posee restos vegetales: algas y ramitas.

Estrato $N^{\circ}$ 4. Composición de arena color amarillento no compacto. Presencia de restos orgánicos: moluscos,

pescados, osamentas humanas y animales.

Estrato $N^{\circ}$ 5. Composición de arena fina color gris no contaminada. Se registra ubicación de 23 faldellines manufacturados en fibra vegetal, sin uso y plegados cuidadosamente. 


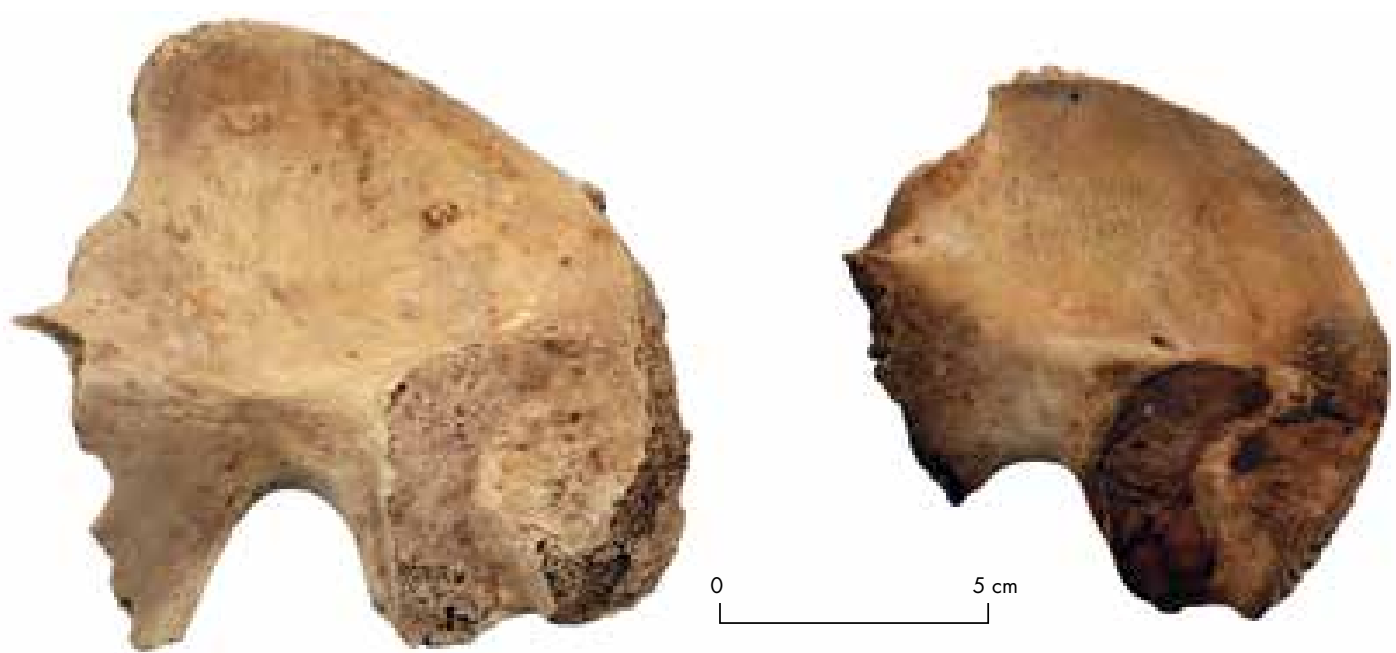

Figura 6. Restos óseos: iliones de un joven y un niño.

Figure 6. Bone remains, fragments of the illia of a young man and a boy.

Tabla 2. Dataciones radiocarbónicas, estrato 4, sitio cueva La Capilla.

(Calibración realizada con curva Incal 09, Programa OxCal 4.1 Curva Incal 09).

Table 2. Radiocarbon dating of strata 4, La Capilla cave.

(Calibration performed with OxCal 4.1 Program using the Incal 09 Curve).

\begin{tabular}{|c|c|c|c|c|c|}
\hline Laboratorio & Muestra & Edad ${ }^{14} \mathrm{C}$ AP & Error & $\begin{array}{c}\text { Edad calibrada } \\
1 \sigma\end{array}$ & $\begin{array}{c}\text { Edad calibrada } \\
2 \sigma\end{array}$ \\
\hline $\begin{array}{c}\text { R_Date Gakushuin } \\
\text { University }\end{array}$ & $\begin{array}{c}\text { Hueso } 1 \text { Sample } \\
\mathrm{N}^{\circ} 2 \\
\text { Cuadrícula } 4\end{array}$ & 2790 & 140 & 1129-806 AC & $1397-593 \mathrm{AC}$ \\
\hline $\begin{array}{c}\text { R_Date Laboratory New } \\
\text { Jersey, EE. UU. }\end{array}$ & $\begin{array}{l}\text { Hueso Sample } \\
\mathrm{N}^{\circ} 7 \\
\text { Cuadrícula } 4\end{array}$ & 3450 & 90 & $1887-1643$ AC & 2010-1529 AC \\
\hline $\begin{array}{c}\text { R_Date Gakushuin } \\
\text { University }\end{array}$ & $\begin{array}{c}\text { Hueso } 1 \text { Sample } \\
N^{\circ} 1 \\
\text { Cuadrícula } 4\end{array}$ & 3670 & 160 & $2292-1782$ AC & $2547-1638 \mathrm{AC}$ \\
\hline
\end{tabular}

\section{LAS PICTOGRAFÍAS: PINTANDO EL MUNDO DE COLOR ROJO}

En la cueva hay una gran cantidad de pictografías dañadas en el transcurso del tiempo por el guano acumulado de las aves marinas que hicieron de ella su albergue y, también, por la acción de personas (figs. 7 y 8). Estas pinturas se distribuyen en dos paneles; el panel 1 (fig. 9) se encuentra al costado derecho de la entrada y el panel 2 (fig. 10) se halla frente a la entrada de la cueva. En el panel 1 se identificaron 28 figuras y en el panel 2, 83 figuras. En total se reconocieron 111 figuras, aunque varias de estas se encuentran muy dañadas y son imposibles de reconocer. La característica principal de este conjunto rupestre es la utilización del color rojo "sangre fresca", denominación dada por
Niemeyer (1972) para las pinturas rupestres de la sierra de Arica. De acuerdo con la escala de Munsell, el color se asemeja al 10R 4/6. ${ }^{1}$

$\mathrm{Al}$ comprobarse una gran similitud entre las figuras se optó metodológicamente por agruparlas en cuatro grupos de diseños (Gráfico 1 y fig. 11): antropomorfos, zoomorfos, geométricos circulares y geométricos lineales, estos a su vez se subdividieron en diferentes tipos que a continuación describimos.

Los diseños antropomorfos incluyen tres tipos. El primero agrupa figuras en posición vertical con sus extremidades inferiores a la altura de los hombros; las líneas se confunden, apreciándose en forma difusa las extremidades superiores y la cabeza. El segundo tipo caracteriza una figura en posición recostada con las extremidades hacia arriba. Su cuerpo en la parte inferior 


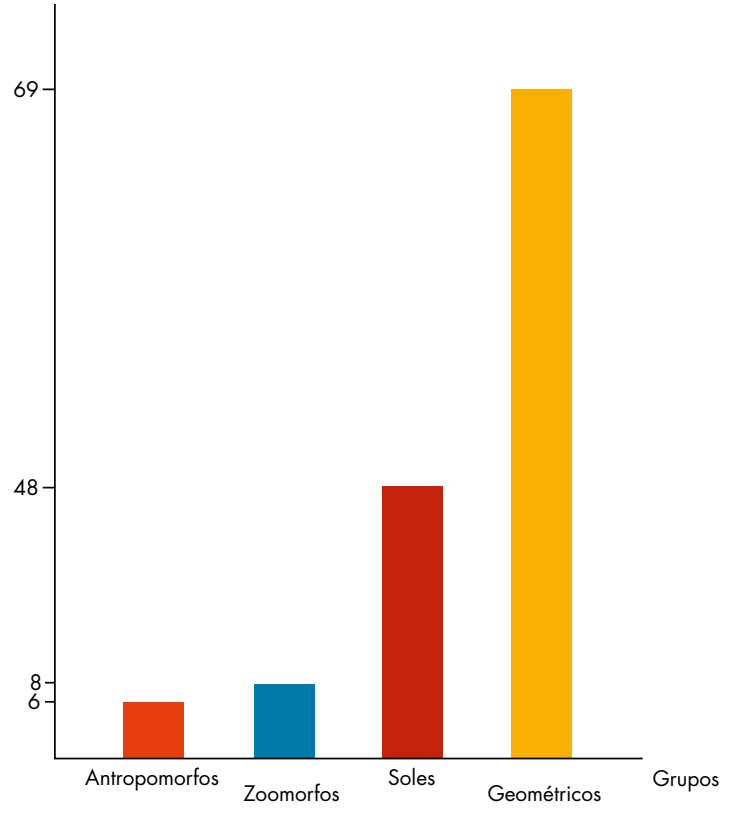

Gráfico 1. Histograma de elementos figurativos de cueva La Capilla. Comparación de cantidad total de elementos por grupo. Graph 1. Histogram of figurative elements found at La Capilla cave. Comparison of total number of elements per group. es un trazo grueso que va angostándose hacia arriba hasta la altura de los hombros, donde sobresale unos centímetros, dando el aspecto de cabeza. El tercer tipo constituye una figura que carece de extremidades inferiores, se observa el tronco y las extremidades superiores dobladas hacia abajo o hacia arriba.

Los diseños zoomorfos integran tres tipos. El primero lo representan figuras de camélidos de carácter naturalista. El segundo tipo lo constituyen figuras de batracios, las que están formadas por un tronco bastante corto y grueso que posee extremidades superiores e inferiores extendidas desde sus costados e inclinadas hacia la parte superior. Las extremidades inferiores terminan en algunos casos en un trazo perpendicular formando una letra T. El tercer tipo corresponde a figuras con forma de lagartos, las que están formadas con una línea recta que se va adelgazando desde un extremo ancho hasta terminar en punta. En ambos costados se observan dos trazos, paralelos entre sí, que sobresalen hacia afuera, en forma oblicua o recta.

Los diseños geométricos circulares se dividen en dos grupos, soles con puntas y soles sin puntas, que a su vez se subdividen en varios tipos. El primero incluye

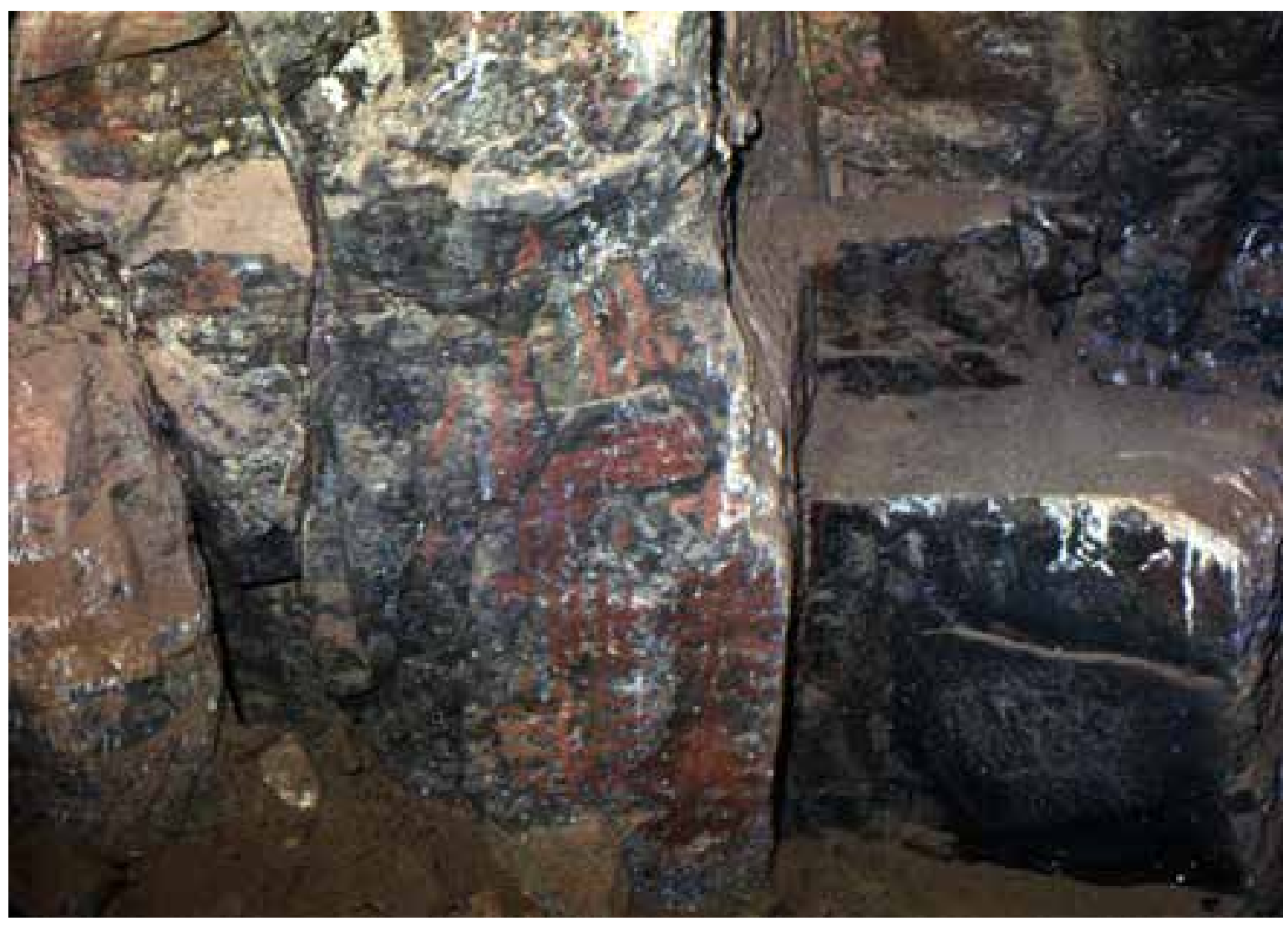

Figura 7. Pinturas del sitio cueva La Capilla, formas geométricas. Panel 2, cota 8,79 m. Figure 7. Paintings of geometric shapes at La Capilla cave. Panel 2, altitude $8.79 \mathrm{~m}$. 


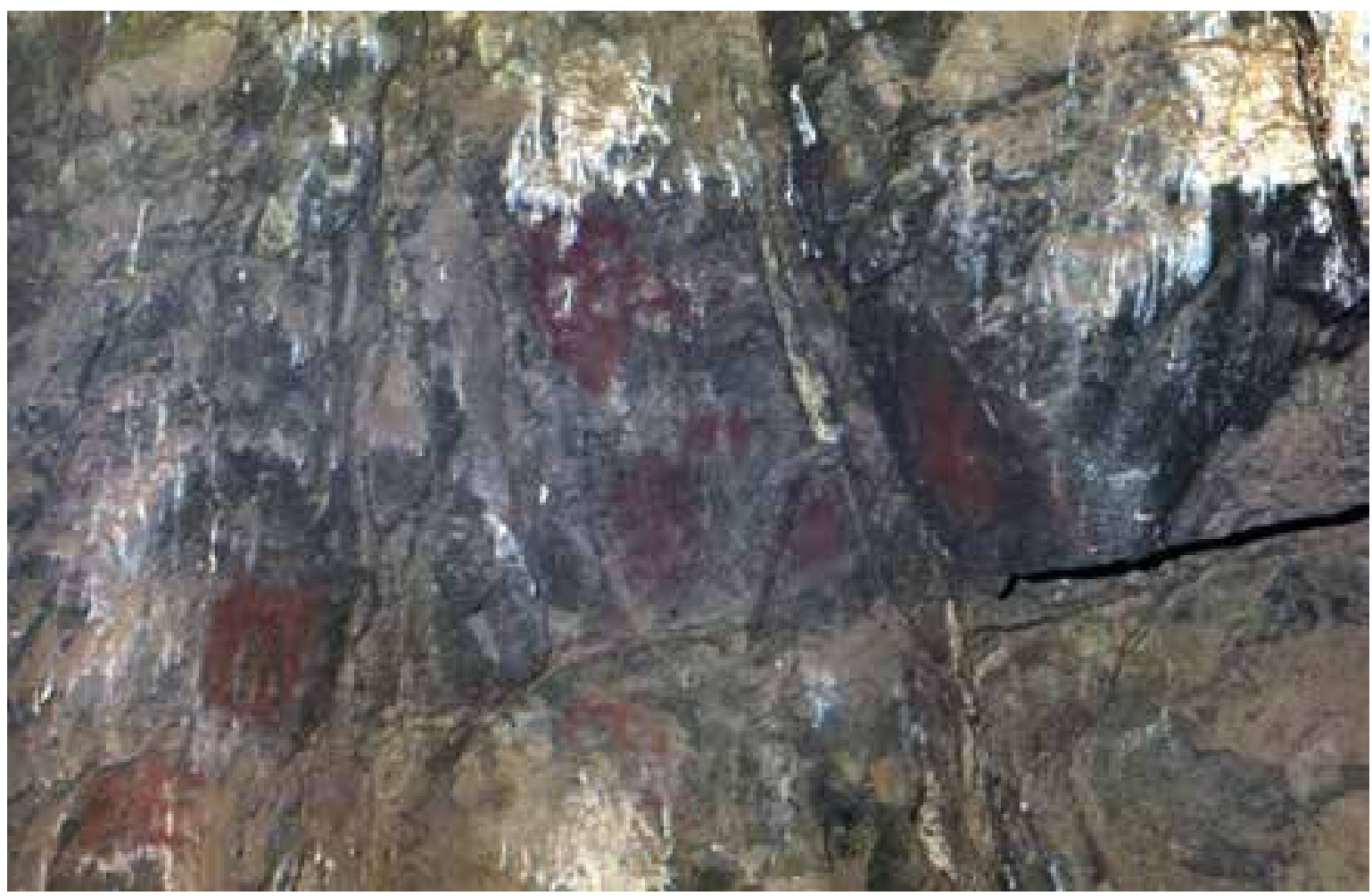

Figura 8. Cueva La Capilla. Panel 2, cota 6,23 m.

Figure 8. Panel 2 La Capilla cave, altitude $6.23 \mathrm{~m}$.

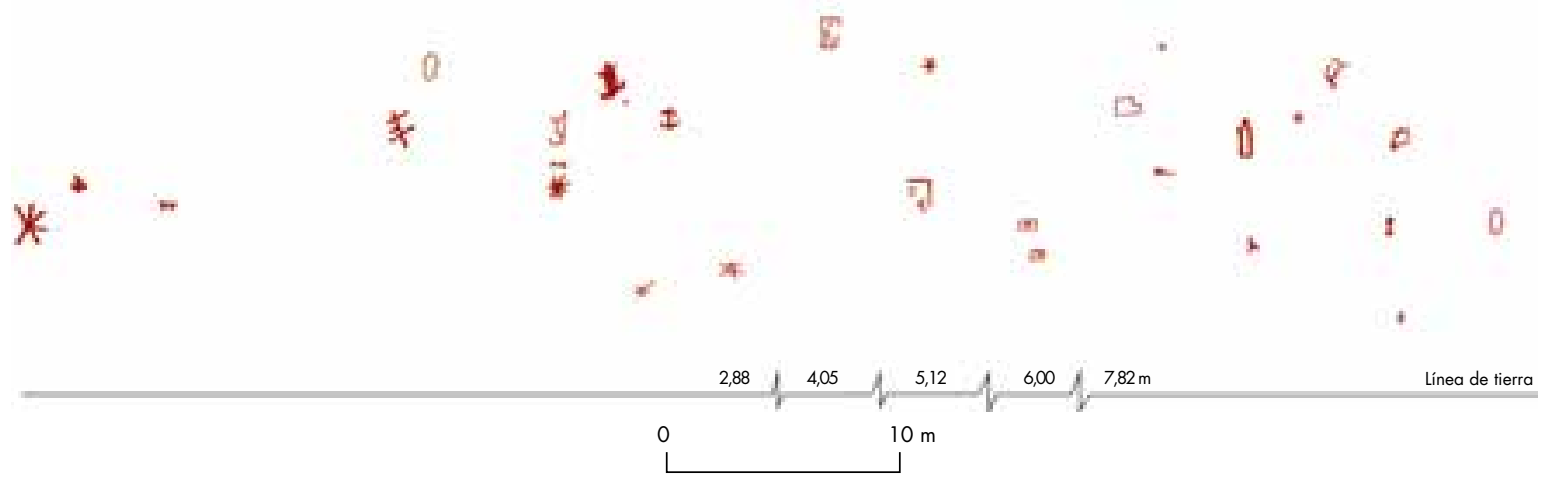

Figura 9. Cueva La Capilla, pictografías panel 1. Escala aproximada 1:25. Relevamiento y dibujo: M. González (1979). Digitalización: R. Rocha (2013). U. Tarapacá.

Figure 9. Pictographs of Panel 1, La Capilla cave. Approximate scale 1:25. Survey and drawing: M. González (1979). Digitization: R. Rocha (2013). U. Tarapacá.

diseños con forma de semicircunferencia con algunos rayos en la periferia. El segundo tipo se caracteriza por una circunferencia pintada totalmente en la parte inferior y con algunos rayos en el exterior. El tercer tipo se conforma por una circunferencia con rayos en el exterior. El cuarto tipo lo constituye una circunferencia pintada totalmente pero en forma muy difusa con rayos en el exterior.
Respecto de los soles sin punta, el primero se caracteriza por una circunferencia pintada en forma muy débil. El segundo tipo es muy similar al anterior, pero su forma básica es elíptica.

Los diseños geométricos lineares son figuras formadas por líneas rectas y curvas de diferentes longitudes y espesores. En estos diseños observamos varios tipos: el tipo 1 presenta líneas paralelas unidas por líneas 


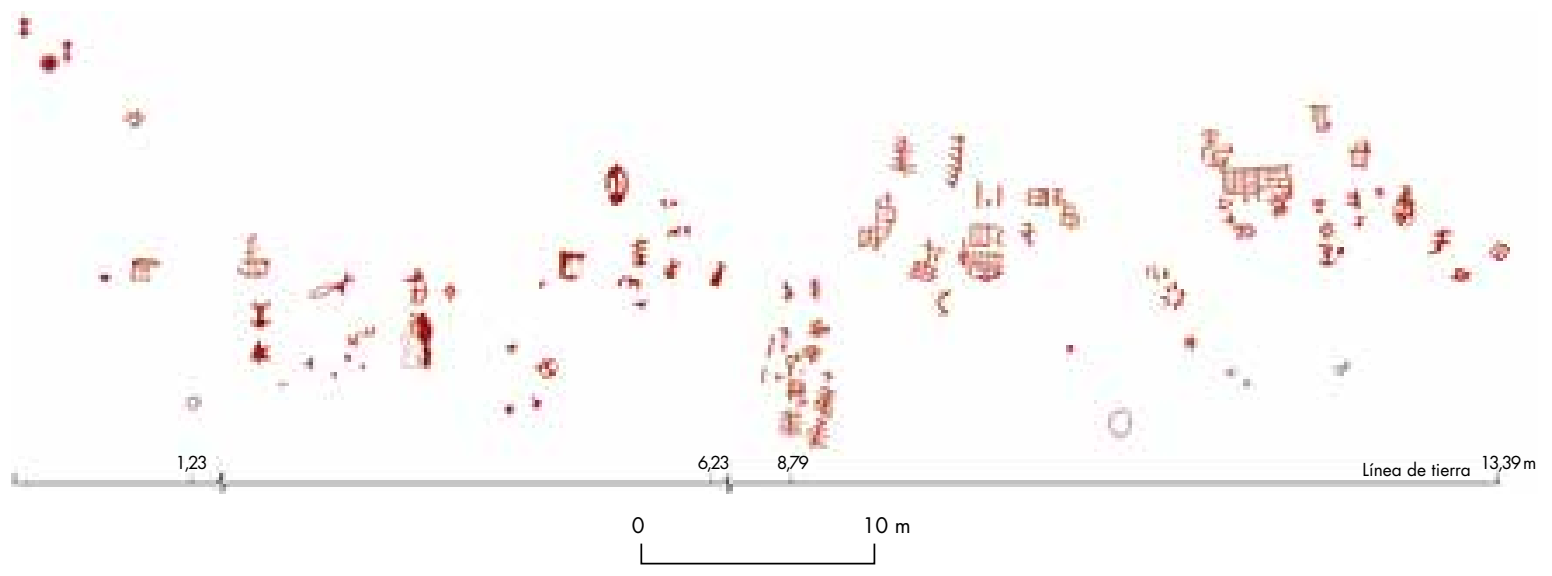

Figura 10. Cueva La Capilla, pictografías panel 2. Escala aproximada 1:25. Relevamiento y dibujo: M. González (1979). Digitalización: R. Rocha (2013). U. Tarapacá.

Figure 10. Pictographs of Panel 2, La Capilla cave. Approximate scale 1:25. Survey and drawing: M. González (1979). Digitization: R. Rocha (2013). U. Tarapacá.

transversales formando una escalerilla. El tipo 2 corresponde a líneas rectas, las que se entrecruzan con líneas verticales y horizontales formando un cuadriculado. El tipo 3 muestra líneas rectas horizontales u oblicuas que van atravesadas por una línea central vertical. El tipo 4 exhibe polígonos regulares e irregulares, algunos de los cuales llevan figuras en su interior. El tipo 5 se caracteriza por figuras complejas formadas por líneas rectas y curvas que se entrecruzan. El tipo 6 lo constituyen figuras complejas formadas por una línea vertical y diagonal, dos a cada lado. El tipo 7 define una figura de forma ovoidal, que se encuentra separada por una línea longitudinal y dividida por líneas transversales formando cuadrados y una semicircunferencia. El tipo 8 agrupa a las figuras no identificadas.

La relación entre la ocupación de la cueva, estrato 4, con las pinturas la hemos establecido según tres variables:

1) En la estratigrafía fueron encontrados varios pigmentos de color rojo, del mismo color con que fueron hechas las pictografías de las paredes de la cueva.

2) En el estrato se encontraron restos de bolsitas confeccionadas en piel y cuero de ave, en cuyo interior se hallaron restos de pigmentos de colorantes, similares a los encontrados en el piso de ocupación; además se halló una mano de moler junto a un mortero. Ambos artefactos presentan en sus superficies restos de óxido de hierro, evidenciando su uso en la preparación de las pinturas.

3) El análisis químico de las muestras encontradas en estratigrafía, así como los residuos de pintura hallados en los restos de bolsitas, las muestras de las pictografías y las muestras tomadas de la pared rocosa de la cueva, arrojan como resultado un alto contenido de hierro en su composición, lo que los hace similares e indica una relación estrecha en el tratamiento de las muestras (Figueroa 1982: 96).

\section{IMPLEMENTOS TECNOLÓGICOS DE LA VIDA COTIDIANA}

Variadas son las tecnologías que se encontraron en la cueva La Capilla. En un porcentaje mayor aparecen las relacionadas con la pesca y la recolección, que corresponden a pesas líticas para anzuelos compuestos, anzuelos de quisco, chopes (desconchadores), arpones de madera con cabezal de hueso y lienzas confeccionadas en totora y algodón (figs. 12, 13 y 14). También fueron halladas pesas de piedras sin trabajar utilizadas para redes, varias de ellas unidas mediante un cordelillo a un fragmento de red de fibra vegetal de diverso grosor (fig. 15). Finalmente se encontró una bolsa tejida con técnica de malla, confeccionada con fibra vegetal. Este tipo de bolsa sirvió para llevar implementos de pesca y recolección (fig. 16). Estos artefactos tienen una larga tradición tecnológica en los pescadores desde hace 6000 años; además, es evidente que para confeccionar estos instrumentos tuvieron que recurrir a los recursos naturales que les proporcionaba el medio, en especial la costa. Ahí obtuvieron huesos de mamíferos marinos, conchas, cantos rodados, algas, etc., y en las desembocaduras de los ríos San José y Lluta recolectaron fibras vegetales y maderas para confeccionar vestimentas y objetos domésticos y ceremoniales.

Uno de los instrumentos hallados en la ocupación de La Capilla fue un cuchillo confeccionado en concha 
ANTROPOMORFOS

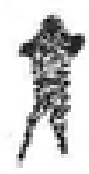

1

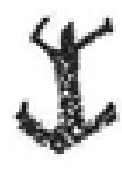

2

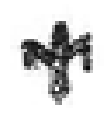

3
ZOOMORFOS
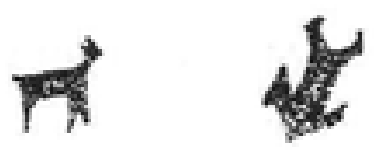

2

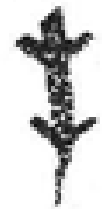

3

SOLES

CON PUNTA<smiles>CC(C)C(C)C(C)(C)C(C)(C)C(C)(C)C</smiles>
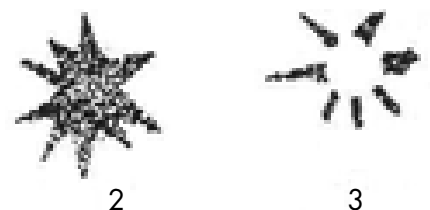

3

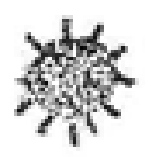

SIN PUNTA

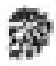

4

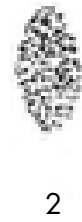

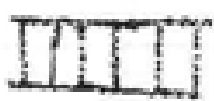

1

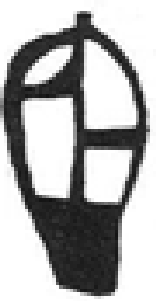

5

GEOMÉTRICOS
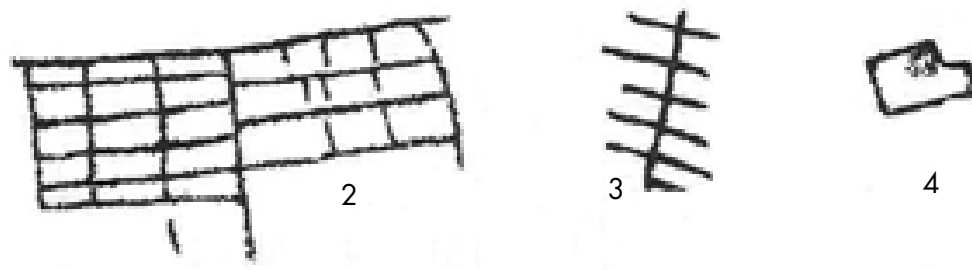

4
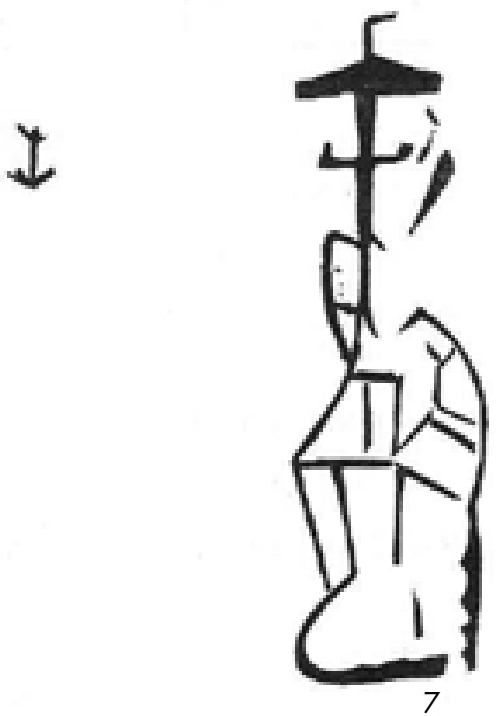

Figura 11. Clasificación de los grupos pictográficos de cueva La Capilla (Muñoz \& Chacama 1982: 35).

Figure 11. Classification of pictographic groupings at La Capilla cave (Muñoz E Chacama 1982: 35). 


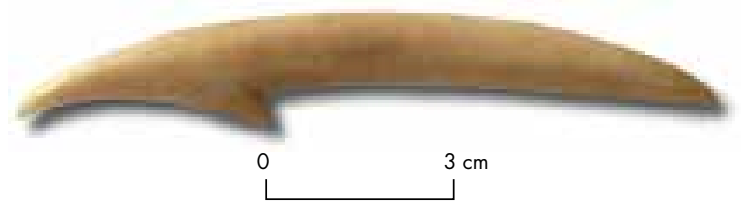

Figura 12. Barba de hueso. Utensilio de pesca. Figure 12. Bone barb. Fishing utensil.

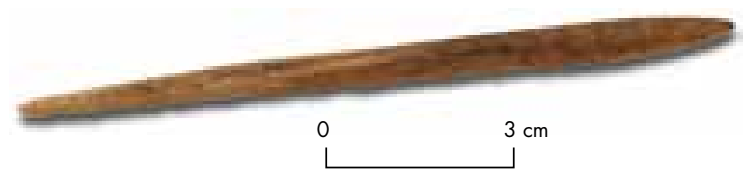

Figura 13. Barba de hueso. Utensilio de pesca. Figure 13. Bone barb. Fishing utensil.

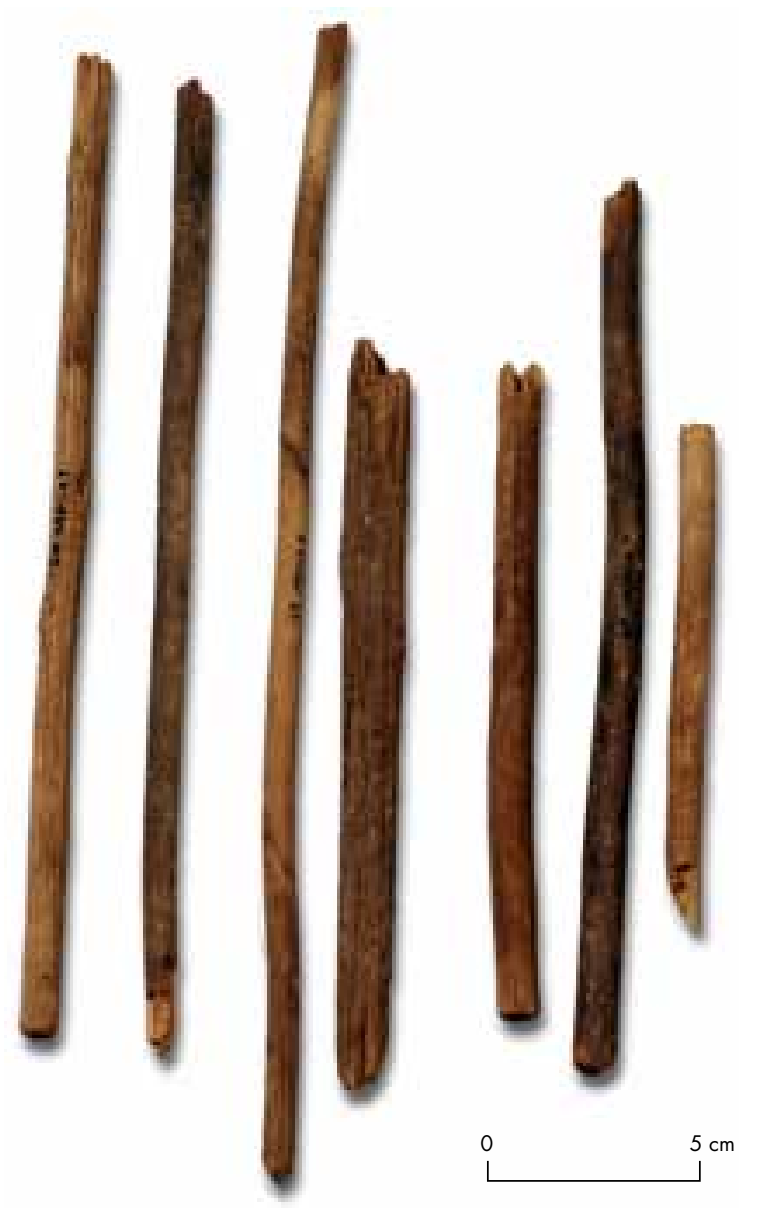

Figura 14. Astiles. Figure 14. Shafts.

de choro, con un borde rebajado por desgaste que le permite cumplir la función de un instrumento cortante. Junto a él se encontraron algunas lascas trabajadas en calcedonia, cuyos extremos presentan un retoque fino a presión que habría permitido rasgar y cortar. También fue hallado un cesto con forma de plato confeccionado

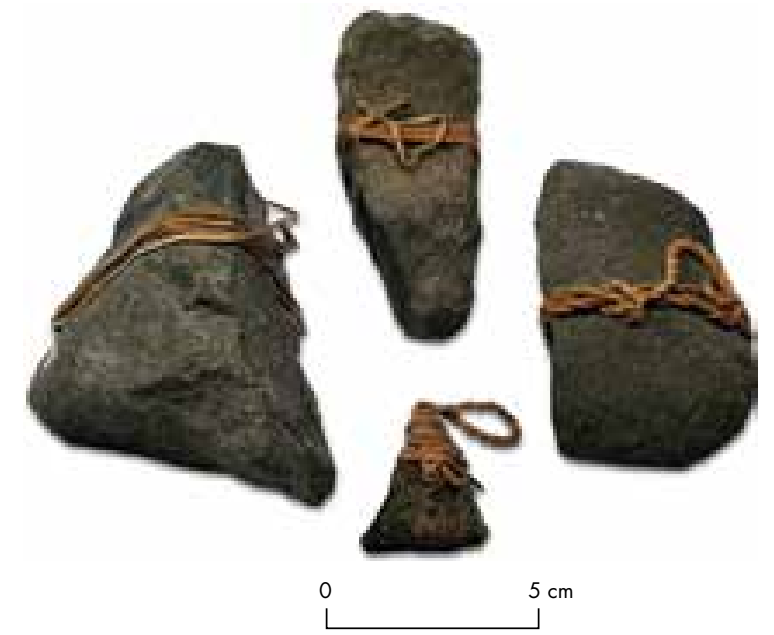

Figura 15. Líticos con amarras de fibra vegetal, posiblemente cumpliendo la función de pesas.

Figure 15. Stones with plant fiber ties, possibly used as fishing weights.

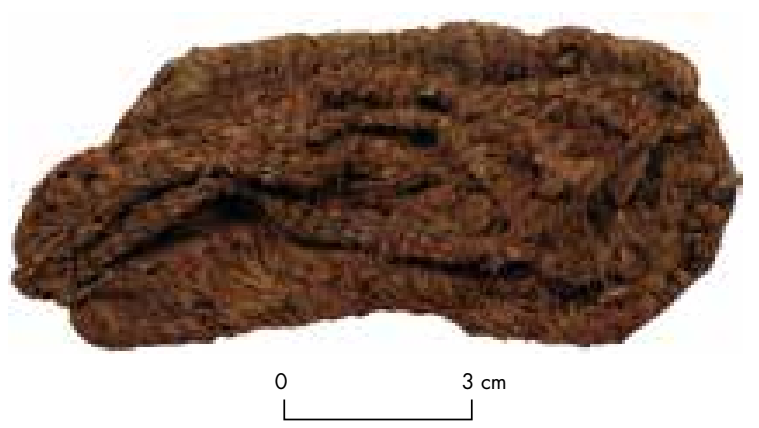

Figura 16. Bolsa tipo malla confeccionada en fibra vegetal. Figure 16. Net bag made of plant fiber.

con un sistema de aduja, pieza que pudo haber sido utilizada para el traslado de objetos ceremoniales al interior de la cueva (fig. 17). Este tipo de manufactura comienza a aparecer con mayor frecuencia en la costa a partir del Período Arcaico Tardío, lo que lo hace ser uno de los artefactos domésticos depositados con mayor frecuencia en las ofrendas rituales fúnebres. Junto a la cestería se encontró un fragmento de hueso de ave embarrilado por un cordelillo de fibra vegetal y un manojo de algas marinas amarradas con fibras vegetales (fig. 18). Ambos objetos pudieron haber sido utilizados como ornamentos decorativos por parte de las personas que participaron en las distintas ceremonias. También fue hallado un fragmento de estera de totora, pieza que debió haber servido para cubrir un volumen o espacio durante los ritos de iniciación. De igual forma, se recolectaron semillas de algodón (Gossypium barbadense), fragmentos de calabaza (Lagenaria sp.) y un fragmento de ostión (Crassostrea sp.) que pudieron 


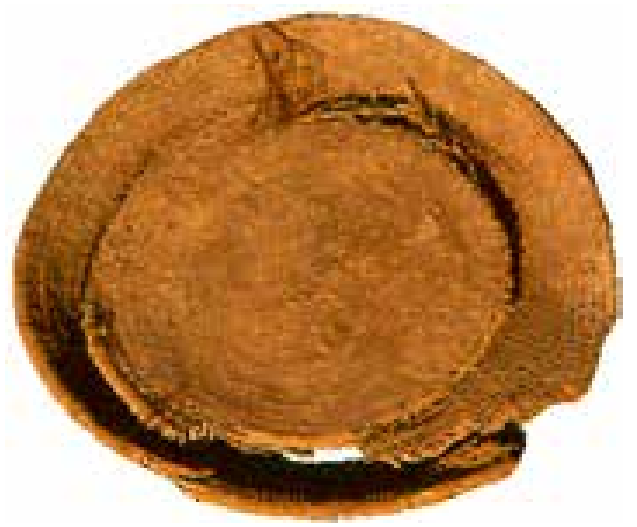

Figura 17. Plato manufacturado en fibra vegetal. Figure 17. Dish manufactured of plant fiber.

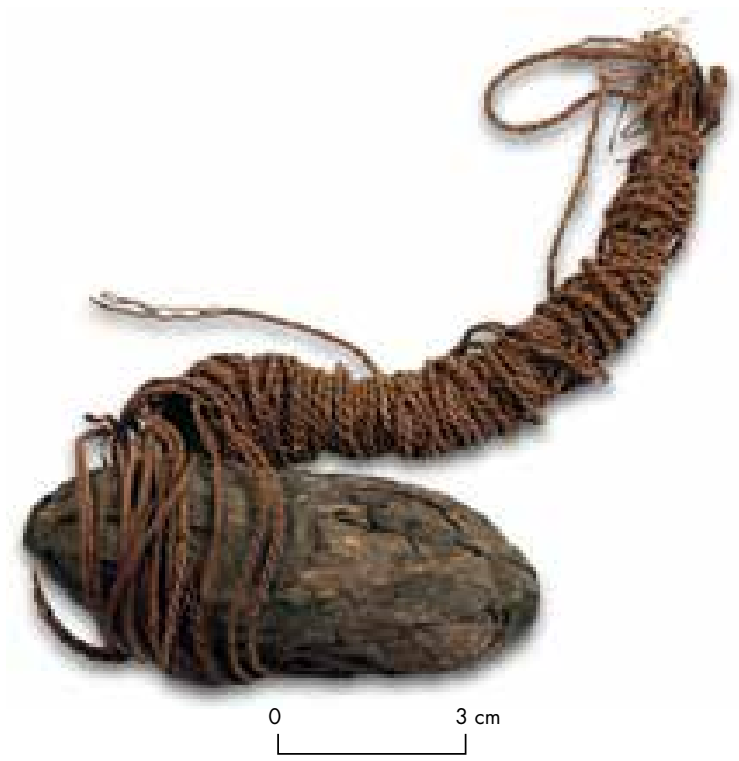

Figura 18. Envoltorio de algas e hilados de fibra vegetal. Figure 18. Wrapping of seaweed and plant fiber cord.

haber sido utilizados como recipientes de servido de comida (figs. 19, 20 y 21).

El hallazgo de un mortero y mano de moler con restos de pintura roja es significativo, ya que junto a los restos de bolsas de piel de ave, en cuyo interior se encontraron restos de pigmentos de óxido de hierro, conforman los implementos básicos con que los pescadores pintaron los muros de la cueva (fig. 22).

A pesar de la escasez de fogones al interior de la cueva, desde el punto de vista tecnológico es interesante el hallazgo de un madero encendedor o quemador (fig. 23), que presenta dos perforaciones de aproximadamente $1 \mathrm{~cm}$ de diámetro con evidencias de quemaduras. Esto hace suponer que en alguna ocasión prepararon fuego al interior de la cueva, probablemente durante
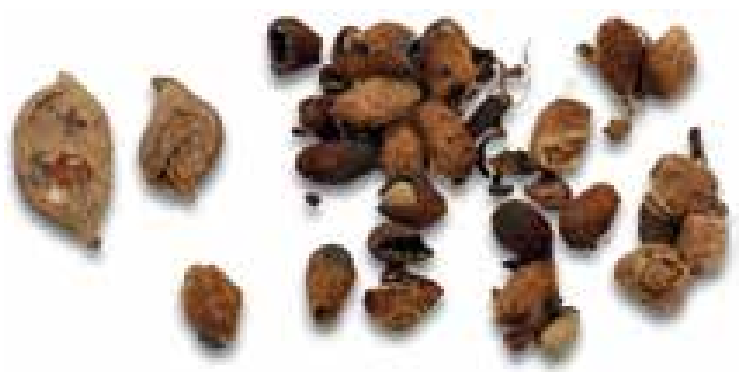

Figura 19. Semillas de algodón y otros.

Figure 19. Cotton and other seeds.

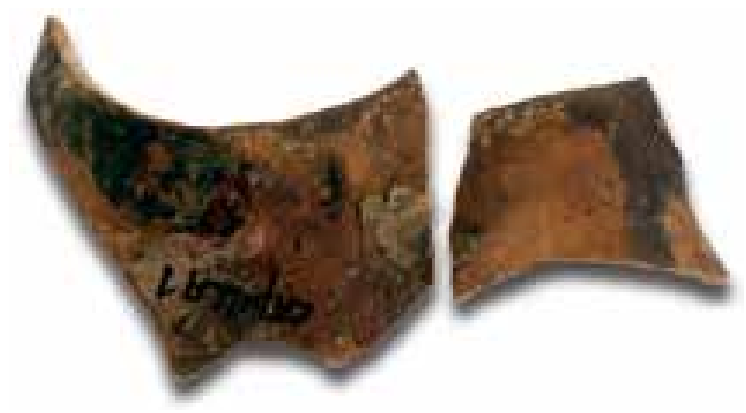

Figura 20. Fragmentos de calabaza.

Figure 20. Gourd fragments.

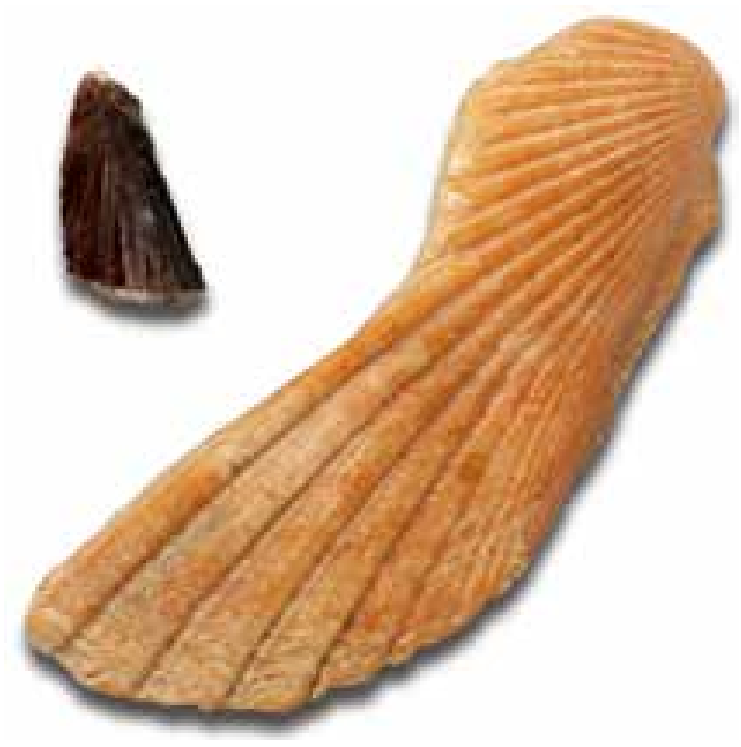

Figura 21. Fragmentos de ostiones.

Figure 21. Scallop shell fragments.

las ceremonias de iniciación más que en la preparación de comidas, las que pueden haberse realizado fuera de la cueva. Planteamos esta hipótesis debido a que en los alrededores de la cueva hemos hallado restos de desechos de alimentos y fogones, una clara señal de preparación de alimentos. 


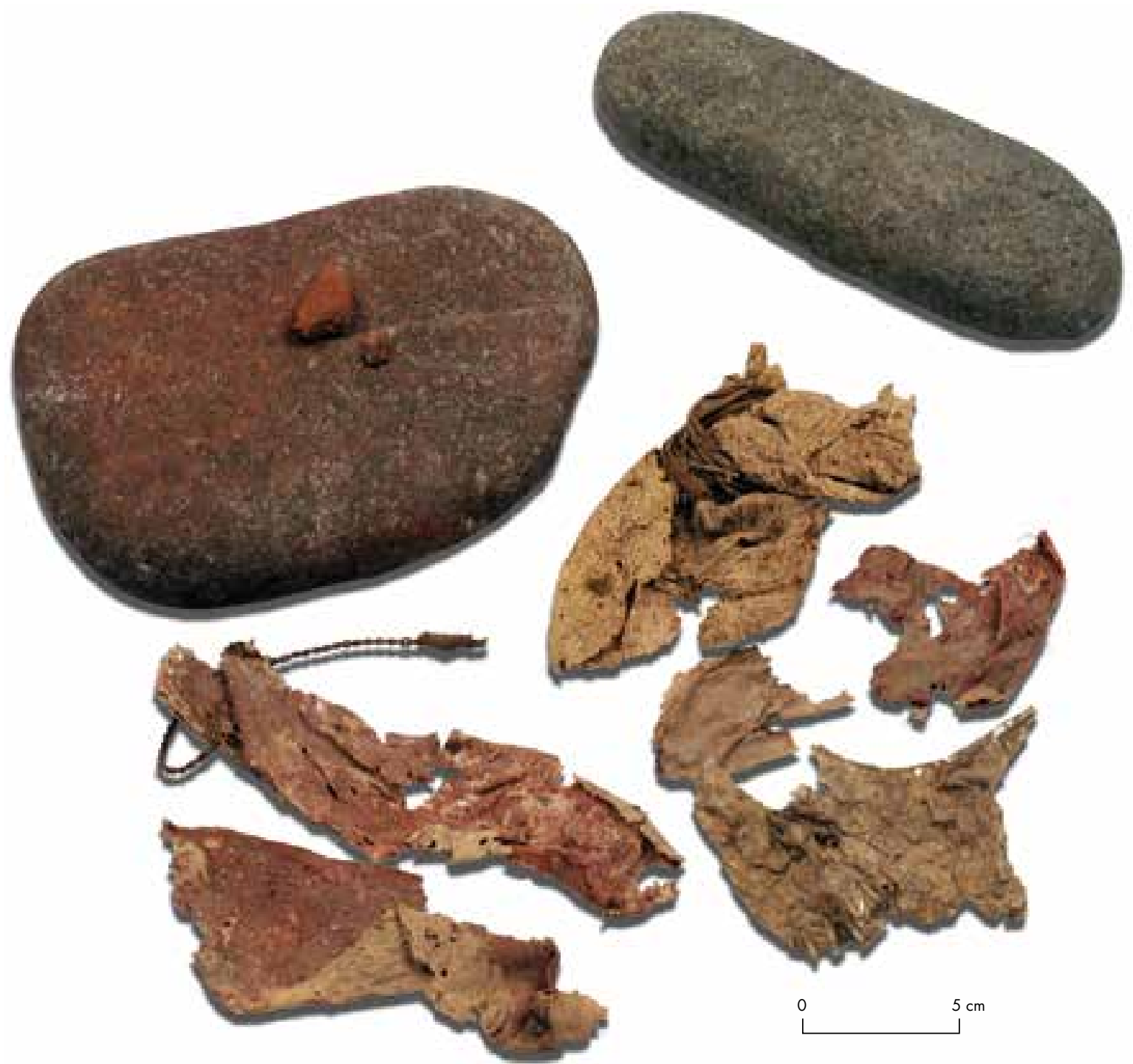

Figura 22. Pigmentos, morteros y envoltorio de piel de ave. Figure 22. Pigments, mortars and bird skin wrapping.

Uno de los rasgos de mayor presencia arrojada por la excavación fueron numerosos restos de cordelillos, constituyendo un indicador relevante en cuanto a las manufacturas (figs. 24 y 25). En un porcentaje mayor fueron confeccionados en fibra vegetal (90\%), algodón (8\%) y algas marinas (2\%); se elaboraron de distintos tamaños para la confección de lienzas, redes, y vestimenta, en especial faldellines y cobertores púbicos.

En cuanto a la vestimenta, la más representativa la constituyen faldellines y cobertores púbicos; los faldellines asemejan formas de delantal, corresponden a haces de totora macerada que penden de un cordón torcido que hace las veces de cinturón (figs. 26 y 27). Diez de estos faldellines se hallaron en el estrato 4 (cultural) y

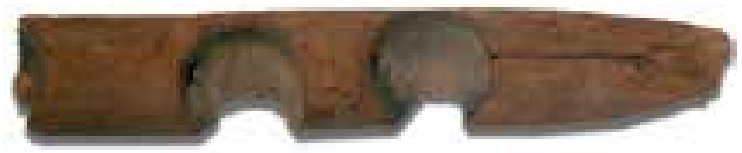

Figura 23. Fragmento de encendedor de madera. Figure 23. Fragment of a wooden fire lighter.

23 en el estrato 5 (arena), sin asociación cultural. Los que se hallaron en el estrato 4 se encuentran bastante impregnados de guano de ave marina, probablemente producto del contacto con los componentes orgánicos del estrato, lo que pudo haber provocado el deterioro paulatino de ellos. Los hallados en el estrato 5 no presentan uso, sus haces de totora se ven uniformes y bien 

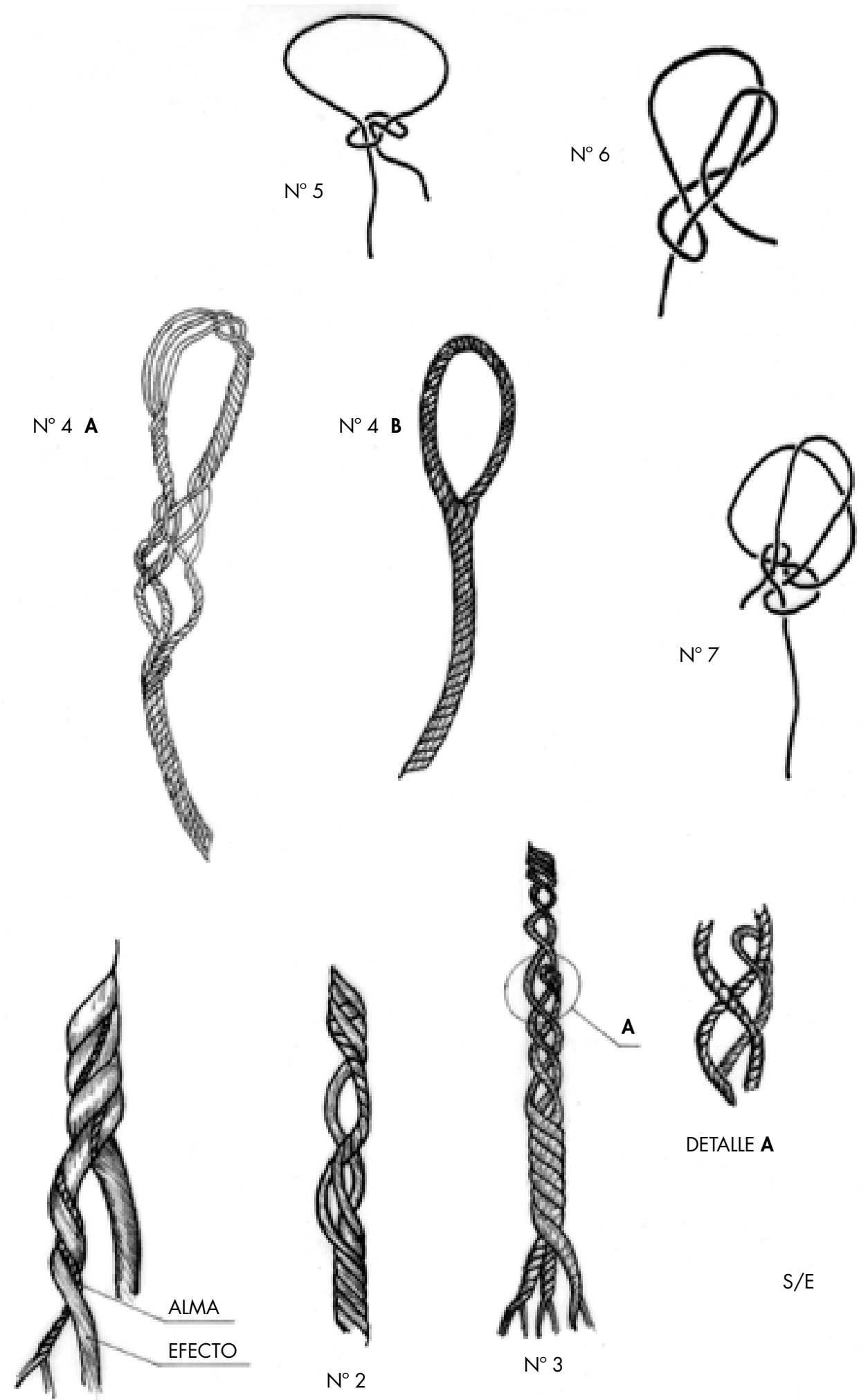

$\mathrm{N}^{\circ} 1$ 


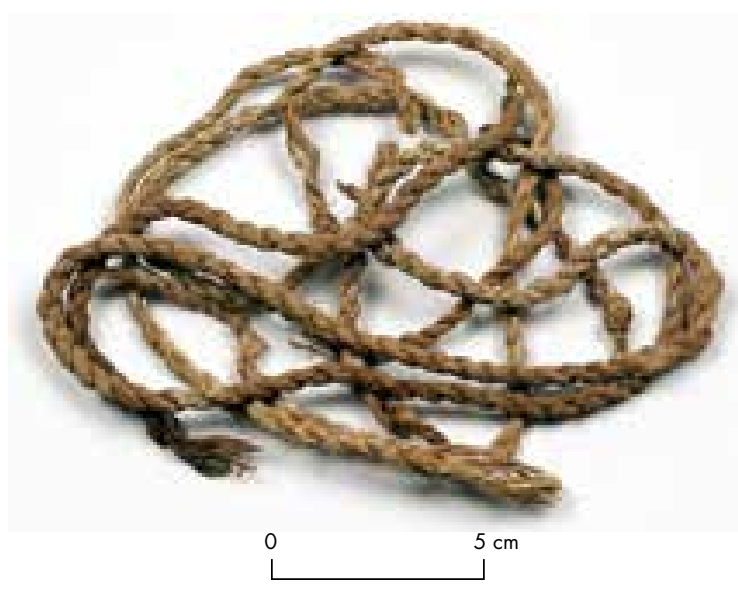

Figura 25.Cordelería de fibra vegetal. Figure 25. Plant fiber cord.
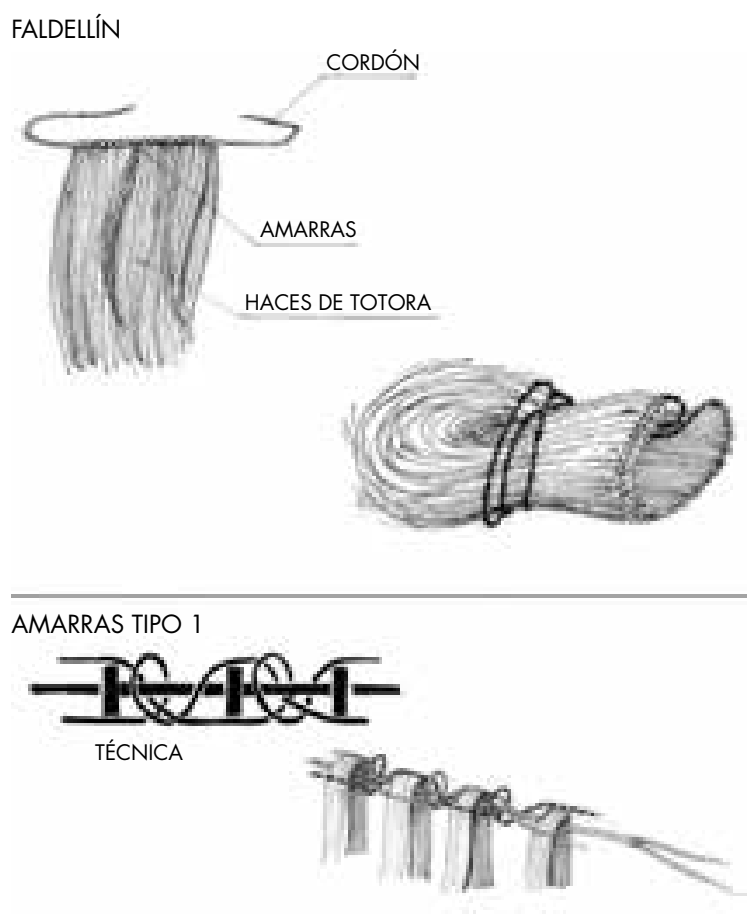

AMARRAS TIPO 2

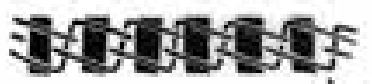

TÉCNICA

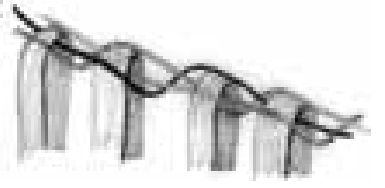

Figura 26.Técnicas de amarra para faldellines.

Figure 26. Techniques used to make grass skirts.

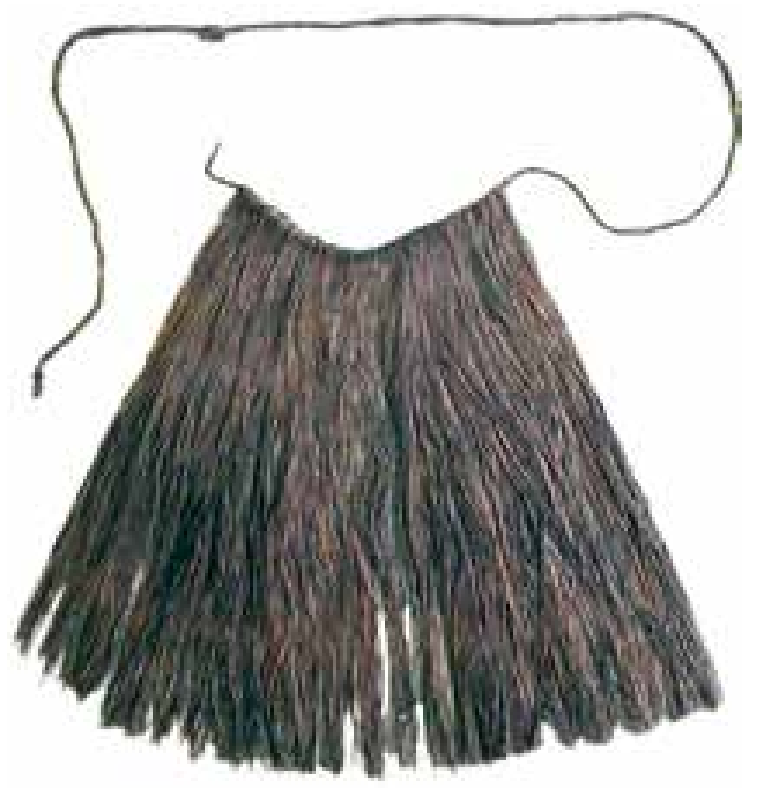

Figura 27. Faldellín de fibra vegetal en cueva La Capilla Figure 27. Plant fiber skirt found in La Capilla cave.

conservados. Su buen estado puede ser producto del medio donde fueron depositados, estrato que presenta menor humedad, además que no fueron afectados por el excremento de las aves.

Algo muy particular de todos los faldellines del estrato 5 es que se encuentran doblados y amarrados, indicando una intencionalidad: los faldellines fueron guardados $\mathrm{o}$ depositados con el fin de preservarlos en el estrato arenoso. En cuanto a su técnica de confección puede decirse, en rasgos generales, que todos están confeccionados de la misma manera, siendo diferentes la forma de amarrar los haces al cordón que sirve para sujetarlos a la cintura. En relación con este último punto se han detectado dos técnicas diferentes de amarras, las que son graficadas en la figura 26. El tipo de amarra 1 se encuentra presente en la totalidad de los faldellines que aparecen en el estrato de arena y muy escasos en el estrato cultural. Los hallados en el nivel ocupacional corresponden al tipo de amarra 2, lo que marca una diferenciación técnica.

Una segunda pieza la constituyó el cobertor púbico. En el estrato 4 fueron hallados 17 de estos ejemplares, todos confeccionados en fibra vegetal, utilizando la técnica de amarra (figs. 28 y 29). Estos cobertores varían en sus dimensiones tanto en el largo $(32 \mathrm{a} 63 \mathrm{~cm})$ como en el ancho $(5 \mathrm{a} 16 \mathrm{~cm})$. Su función fue cubrir los genitales $\mathrm{y}$, por sus variadas dimensiones, probablemente fueron usados por individuos de distintas edades, lo que indicaría que en las actividades de la cueva no participaron solo individuos adultos. 


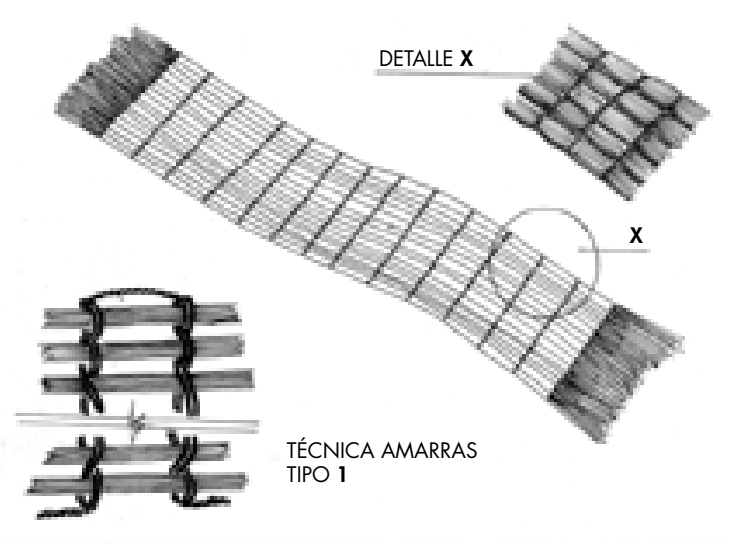

\section{TEJIDOS DE MALLA}

RED -TÉCNICALAZADA CON TORSIÓN (Emery 1966: 31)

FAJA -TÉCNICA-

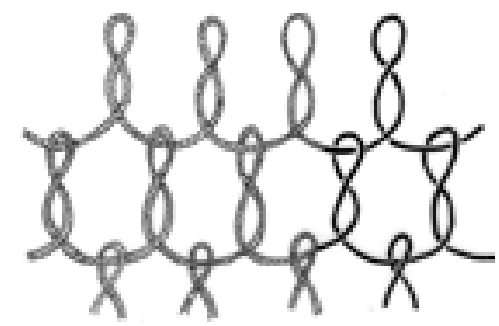

VARIACIÓN DE ESLABONADO (INTERLINKING)

(Emery 1966: 62)

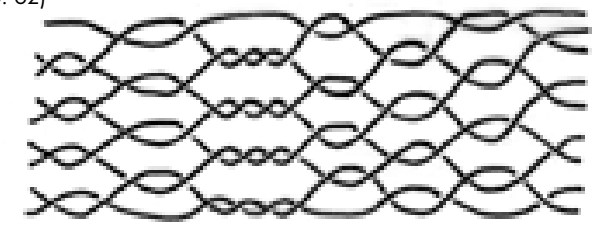

Figura 28. Técnicas tejido de esteras.

Figure 28. Mat weaving technique.

Finalmente, como parte del vestuario textil, hallamos el fragmento de una faja confeccionada en algodón. Por corresponder a un fragmento, es difícil determinar su función, pero hemos hallado prendas similares en entierros de la época, cubriendo la frente del cuerpo a manera de cintillo.

Junto a los implementos tecnológicos anteriormente citados, en la cueva La Capilla hemos encontrado restos de mandioca (Manihot utilissima), camote (Ipomoea batatas) y calabazas (Lagenaria sp.). Si a esto agregamos el zapallo hallado por Dauelsberg (1974) en el cementerio Quiani 7, en la costa sur de Arica, podemos señalar que constituyen las evidencias de cultivos más tempranas para la costa de Arica y que posiblemente fueron plantados en zonas de desembocadura o vertientes del sector bajo del valle de Azapa. El crecimiento de las plantas halladas en La Capilla y Quiani requiere de condiciones climatológicas y de suelo como las que ofrecen los valles costeros de Arica; además, debió haber existido un conocimiento del medio y un seguimiento en cuanto a observar el crecimiento de estas plantas, previo al proceso de adaptación y cultivo. Sin embargo,

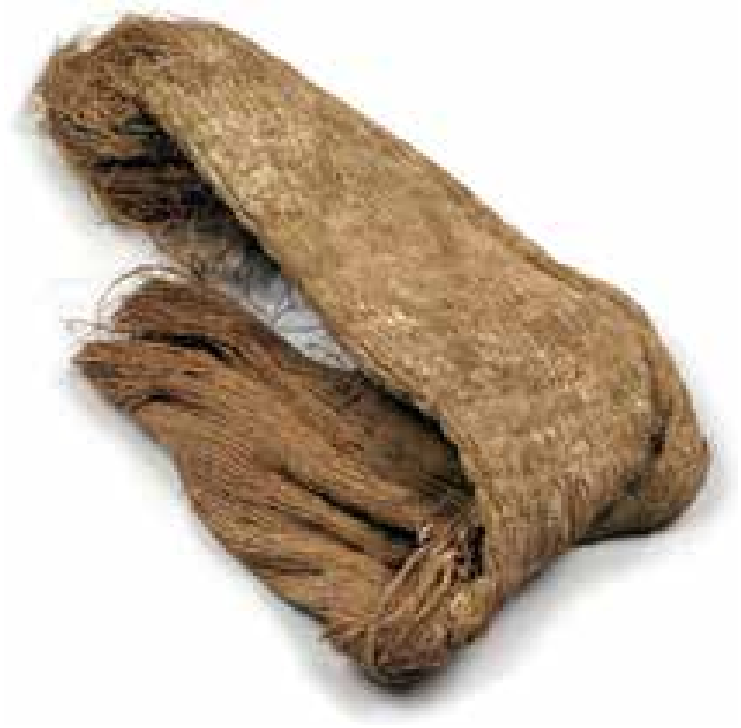

Figura 29. Cobertor púbico hallado en cueva La Capilla. Figure 29. Loincloth found in La Capilla cave.

al margen de las condiciones ambientales favorables para su crecimiento, se necesitó de un tiempo para que dichas plantas se insertaran dentro de este proceso de agriculturación.

En síntesis, la presencia de estos cultivos en la costa, el uso de nuevas tecnologías como la cestería y la textilería confeccionada en lana junto a un incremento de las tecnologías tradicionales de pesca y recolección, son testimonios materiales de los cambios paulatinos que se estaban produciendo en el transcurso del segundo milenio antes de Cristo en los grupos costeros. Su mayor complejidad la vamos a observar a partir del primer milenio antes de Cristo en lo que se conoce como la Fase Azapa o Faldas del Morro, en la cual los grupos de pescadores ya se han asentado a vivir en el valle (Tabla 3).

\section{PAISAJE Y MONUMENTO}

Si consideramos que, desde el punto de vista del paisaje, "el ser humano [...] no solo vive en el entorno sino que crea su propio entorno para vivir, en otras palabras, construye su propio medio sociocultural" (Godelier 1984; Criado 1999: 5), es posible comprender la importancia que tuvo la cueva La Capilla para los pescadores de la costa de Arica que vivieron en torno a ella y, por ende, se comprende también que su estructura física fuese parte del campo simbólico de las poblaciones que la ocuparon. El análisis morfológico del paisaje nos señala que la cueva se halla en un abrupto montículo con una 
Tabla 3. Restos culturales y osamentas humanas halladas en estratigrafía de la cueva La Capilla. ${ }^{2}$ Table 3. Cultural remains and human bones discovered in the layers La Capilla cave.

\begin{tabular}{|c|c|c|c|}
\hline Materialidad & Estrato 4 & Estrato 5 & $\mathrm{~N}^{\circ}$ \\
\hline Pesas de anzuelo compuesto & $\mathrm{x}$ & & 1 \\
\hline Anzuelos de cactáceas sin identificar especie & $\mathrm{x}$ & & 3 \\
\hline Arpón de madera & $\mathrm{x}$ & & 8 \\
\hline Cabezal de arpón & $\mathrm{x}$ & & 2 \\
\hline Flotadores & $\mathrm{x}$ & & 2 \\
\hline Manojo de algas marinas & $\mathrm{x}$ & & \\
\hline Pesas líticas & $\mathrm{x}$ & & 6 \\
\hline Redes de fibra vegetal & $\mathrm{x}$ & & 8 \\
\hline Morteros & $\mathrm{x}$ & & 2 \\
\hline Manos de moler & $\mathrm{x}$ & & 1 \\
\hline Cuchillo de valva de Choromytilus chorus & $\mathrm{x}$ & & 1 \\
\hline Encendedor/yesquero & $\mathrm{x}$ & & 2 \\
\hline Cestería & $\mathrm{x}$ & & 1 \\
\hline Cobertores púbicos & $\mathrm{x}$ & & 17 \\
\hline Faldellines & $\mathrm{x}$ & $\mathrm{x}$ & $10 / 23$ \\
\hline Bolsa tejida con técnica de malla (punto red) & $\mathrm{x}$ & & 1 \\
\hline Chopes de hueso & $\mathrm{x}$ & & 2 \\
\hline Fragmento de bolsa de piel y cuero de ave & $\mathrm{x}$ & & 3 \\
\hline Pigmentos de pintura roja & $\mathrm{x}$ & & \\
\hline Tejido tipo faja & $\mathrm{x}$ & & 1 \\
\hline Estera de totora & $\mathrm{x}$ & & 1 \\
\hline Cordelillos & $\mathrm{x}$ & & 26 \\
\hline \multicolumn{4}{|l|}{ Restos de óxido de hierro } \\
\hline Fragmento de calabazas & $\mathrm{x}$ & & 1 \\
\hline Fragmento de ostión & $\mathrm{x}$ & & 1 \\
\hline Osamentas humanas & $\mathrm{x}$ & & 17 \\
\hline Hueso embarrilado con lana & & & 3 \\
\hline
\end{tabular}

amplia vista al mar, lo que permitió a los pescadores un acceso directo a la explotación de los recursos marinos. Si bien es cierto que hoy es complejo subir los $50 \mathrm{~m}$ que llevan a la entrada de la cueva desde el piso base (nivel del mar) -ya que la pendiente fue cortada para construir la carretera costera que se dirige a playa Corazones-, durante el Período Arcaico Tardío debió existir un sendero que comunicara la entrada de la cueva con tres playas productivas aptas para la explotación del mar: La Capilla, Quiani y Corazones. La primera se relaciona directamente con la cueva y, por la profundidad de sus aguas, es apta para la pesca de cabrillas, congrios y lenguados. La segunda es un espacio propicio para la pesca, por sus arrecifes y acantilados, lugares especiales para la extracción de mariscos, crustáceos y algas. Además, esta playa presenta los mayores recursos acuíferos porque aquí se encuentra la única quebradilla de la costa sur de Arica, lo que la convierte en un lugar atractivo para el asentamiento. La tercera playa, aparte del potencial productivo marino que ofrece, presenta grandes refugios, especiales para asientos de mamíferos marinos (lobos) y avifauna, constituyéndose en un espacio productivo de caza, de gran interés para los pescadores arcaicos.

En la cima de los cerros donde se encuentra la cueva La Capilla, producto de la concentración de neblina, se produce una humedad que favorece el crecimiento de cactáceas, recurso que al parecer fue utilizado en la confección de anzuelos. Desde el punto de vista de 
la visibilidad, es un lugar atractivo en donde es posible avistar las diversas playas del litoral de Arica y la desembocadura del río San José, el mayor ecosistema de recursos hídricos y vegetales explotados por los pescadores arcaicos de la costa de Arica.

La visibilidad que presenta la cueva es ventajosa, ya que además de las playas y la desembocadura está conectada con dos hitos geográficos importantes del litoral sur de Arica, como son El Morro y la quebrada Quiani. Ambos, a su vez, están conectados con el sector bajo del valle de Azapa, específicamente con los sectores de confluencia de la quebrada de Acha y el cerro Chuño. Esta conexión se dio por senderos que habrían permitido el desplazamiento a pie de tempranos pescadores, el que se habría efectuado desde las tempranas ocupaciones de Acha, comunicando el sector de confluencia de las quebradas Azapa-Acha con el sector de Quiani-La Capilla, en la costa.

$\mathrm{Al}$ interior de la cueva, si bien no hay una modificación arquitectónica, es interesante ver que su ocupación está directamente relacionada con la luz solar, situación que se verifica en las paredes laterales de la cueva, donde las pictografías del panel 1 y panel 2 fueron hechas hasta donde alcanzó dicha luz.

Lo que se desprende del análisis del paisaje respecto de la cueva La Capilla y su entorno es que los pescadores mantuvieron este espacio como un lugar que incorporó y evocó una identidad. Las personas reconocen, inscriben, conceptualizan y mantienen colectivamente algunos lugares en el ritual y en los símbolos, por lo tanto, como lo señala Williams (1998), estos lugares crean y expresan la identidad sociocultural del grupo humano. En el caso específico de las cuevas, según Shennan (1994), estas se relacionan con los orígenes, la memoria y con los mitos de fundación de los pueblos originarios. En el caso de los mitos de las poblaciones americanas precolombinas, Florescano (1993) y Broda (2001) señalan que las cuevas se relacionan con las profundidades de la tierra, donde nacieron los seres humanos y desde donde brota el agua, que permitió la fertilidad y la abundancia agrícola. Son lugares de protección y gestación que simbolizan un útero terrenal, es el inframundo o reino subterráneo sumergido en las aguas, donde comienza la vida.

Si consideramos las ideas anteriormente planteadas, podemos sugerir que la cueva La Capilla pudo haber sido una entidad ordenadora dentro del espacio costero, representando el centro sobre el que pudo haberse concebido el mundo de los pescadores. Allí es posible que se hayan normado ideas y catalizado información, muchas de ellas quizás expresadas en las pinturas de las paredes de la cueva y en los rituales de iniciación relacionados al cambio de vestimenta. Al parecer, estos mensajes no solamente fueron percibidos por dichas poblaciones, sino que permanecieron en el tiempo, constituyéndose, como lo señala Geertz (1973: 90), en manifestaciones tangibles del campo de las ideas de los pescadores de la costa de Arica.

Por las características del entorno, las evidencias materiales y las expresiones ideográficas halladas, todo parece indicar que la cueva La Capilla pudo haber constituido un monumento, el que, tal como lo plantean Barrett y colaboradores (1991), tuvo la función de conmemorar, convirtiéndose en un importante espacio transmisor de la cultura de los pescadores. Por ser un espacio cerrado, permitió que los pescadores se concentraran en su interior durante las ceremonias de iniciación, dejando en las paredes un discurso gráficamente bien organizado y equilibrado en cuanto a la distribución de las figuras que conforman los paneles.

La presencia de este temprano monumento en la costa de Arica pudo haber implicado lo que Criado y colaboradores (2000) han llamado "la artificialización de la naturaleza”, señalando que la monumentalidad no aparece de repente, sino de manera gradual. La construcción monumental de la cueva La Capilla pudo haber obedecido a la idea de preservar el orden social de los pescadores en los momentos en que la tradición funeraria Chinchorro estaba desapareciendo, por lo tanto los rituales celebrados en la cueva habrían conducido a nuevas formas de ser y estar en el mundo. Sus pinturas, entonces, tal vez representaron un conjunto de innovaciones simbólicas, sociales y políticas que no pueden asociarse a una mera transformación económica productiva -horticultora- que se estaba desarrollando, sino que obedeció a todo un cambio ideológico que se estaba generando en los pescadores de la región de los valles occidentales (Renfrew 1983; Ingold 1986, 2000; Vicent 1990; Bradley 1993; Filgueiras \& Rodríguez 1994; Hernando 2002).

Una parte fundamental de la caracterización de los monumentos es la complejidad de los ritos y los símbolos que están en juego. Así, las ceremonias que se celebraron en dicha cueva debieron ser complejas, con la participación de un grupo humano organizado, como es posible observarlo al analizar la vestimenta, la tecnología y las representaciones de las pinturas rupestres.

En síntesis, pensamos que en el interior de la cueva La Capilla se habría expresado un sistema de representación propia de los pescadores de la costa de Arica, cuyos testimonios son la cultura material y las pictografías. La cueva constituye así un espacio portador de mensajes simbólicos e ideológicos que, probablemente, sirvieron para homogeneizar el sentido de vivir, marcando una 
cohesión social e identidad entre los pescadores que la habitaron.

\section{COMPLEJIDAD SOCIAL}

El estudio del arte rupestre de la cueva La Capilla, sumado a los hallazgos de tubérculos y cucurbitáceas y nuevas tecnologías, nos permiten discutir el escenario en el que se encontraban los pescadores de la costa de Arica durante el último milenio antes de Cristo. Se puede suponer que las poblaciones que la habitaron por 800 años, aproximadamente, fueron un grupo de pescadores, quienes conocían ampliamente el litoral ariqueño y los valles bajos como Azapa y Lluta, por lo tanto, habrían explotado sus recursos movilizándose por los distintos espacios productivos, siendo la cueva un lugar importante dentro de este circuito de subsistencia.

Pero quizás donde mejor se expresa esta complejidad social es en el arte pictórico. El estudio descriptivo de las figuras permite observar una serie de diseños que están presentes en otro tipo de materialidades respecto de la época, como fueron las calabazas pirograbadas y los diseños en cestería y tejidos. Este arte decorativo se caracterizó por cuatro tipos de diseños, sobresaliendo las figuras geométricas y de soles; también aparecen figuras de camélidos, lo que sería un indicador de la presencia de estos animales en los valles costeros. Un análisis comparativo de los diseños plasmados en calabazas y cestería en ocupaciones del Período Arcaico Tardío y Formativo Temprano en la costa de Arica y Camarones arroja la información contenida en la Tabla 4.

De esta Tabla y de la Figura 30 se desprende que en la costa de Arica habría una tendencia por representar cierto tipo de figuras, las que habrían sido parte de los íconos emblemáticos que caracterizaron a los pescadores de Arica.

Ahora bien, como lo señala Forcano (2000), el análisis de las pictografías de la cueva La Capilla puede iluminar algunos aspectos de la mentalidad de los grupos culturales que lo realizaron. Si bien es cierto que la interpretación de las imágenes es casi imposible, en la ejecución de estas obras gráficas podemos observar el "esqueleto ideológico" de los grupos que las hicieron, constituyendo claros mensajes de los pescadores (LeroiGourhan 1984).

En relación con la representación del espacio pintado, en los paneles se observa una clara estructuración. En el panel 1, en el sector derecho, la mayor cantidad de figuras son geométricas, especialmente de formas rectangulares; las figuras del sector izquierdo, a su vez, tienen formas de soles y son antropomorfas y zoomorfas. En el panel 2 observamos que las figuras geométricas, 25 en total, se hicieron en el sector derecho, agrupadas

Tabla 4. Comparación de diseños de ocupaciones en sitios arqueológicos (Edades calibradas Programa OxCal 4.1).

Table 4. Comparison of occupational designs in archaeological sites (Dated using the OxCal 4.1 Program).

\begin{tabular}{|c|c|c|c|c|c|c|c|}
\hline Sitio & $\begin{array}{c}\text { Muestra } \\
\mathrm{N}^{\mathrm{o}}\end{array}$ & $\begin{array}{c}\text { Edad }{ }^{14} \mathrm{C} \\
\mathrm{AP}\end{array}$ & $\begin{array}{c}\text { Edad } \\
\text { calibrada } \\
1 \sigma\end{array}$ & $\begin{array}{c}\text { Edad } \\
\text { calibrada } \\
2 \sigma\end{array}$ & Período & Diseño & Referencias \\
\hline Quiani-7 & 1 & $3590 \pm 100$ & 2126-1775 AC & 2274-1686 AC & Arcaico Tardío & $\begin{array}{l}\text { Zoomorfo y } \\
\text { geométrico }\end{array}$ & Dauelsberg 1974 \\
\hline Camarones 15 & 1 & $3060 \pm 100$ & 1434-1133 AC & $1520-1017$ AC & Arcaico Tardío & Soles & Rivera et al. 1974 \\
\hline Azapa 14 & 1 & $2640 \pm 110$ & $969-553 \mathrm{AC}$ & 1026-414 AC & $\begin{array}{l}\text { Formativo } \\
\text { Temprano }\end{array}$ & Soles & Santoro 1980a \\
\hline Pl. Miller 7 & 1 & $2480 \pm 100$ & $767-426 \mathrm{AC}$ & 805-396 AC & $\begin{array}{l}\text { Formativo } \\
\text { Temprano }\end{array}$ & $\begin{array}{c}\text { Antropomorfo } \\
\text { y zoomorfo }\end{array}$ & Focacci 1974 \\
\hline Azapa 71 & 1 & $2855 \pm 85$ & $1188-910 \mathrm{AC}$ & $1289-830 \mathrm{AC}$ & $\begin{array}{l}\text { Formativo } \\
\text { Temprano }\end{array}$ & Soles & Santoro $1980 \mathrm{~b}$ \\
\hline Morro 2 & \multicolumn{4}{|c|}{ sin fechado } & $\begin{array}{l}\text { Formativo } \\
\text { Temprano }\end{array}$ & $\begin{array}{c}\text { Antropomorfo, } \\
\text { soles y } \\
\text { geométricos }\end{array}$ & Dauelsberg 1985 \\
\hline Morro 2/2 & 1 & $2770 \pm 80$ & 1006-831 AC & 1188-797 AC & $\begin{array}{l}\text { Formativo } \\
\text { Temprano }\end{array}$ & Geométrico & \multirow{2}{*}{$\begin{array}{c}\text { Focacci \& } \\
\text { Chacón } 1989\end{array}$} \\
\hline Morro-1.6 & 1 & $3750 \pm 140$ & 2429-1973 AC & $2570-1772 \mathrm{AC}$ & Arcaico Tardío & Geométrico & \\
\hline
\end{tabular}




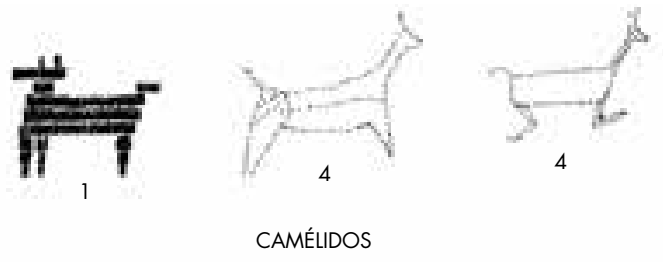

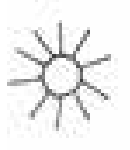

5

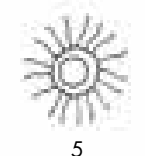

5

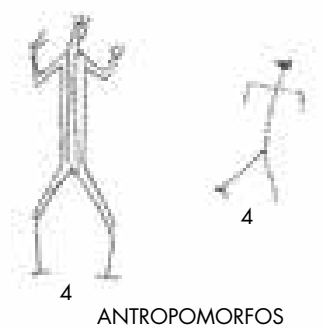

ANTROPOMORFOS

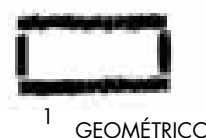

Figura 30. Tipología elementos decorativos Período Arcaico (Muñoz \& Chacama 1982: 382).

Figure 30. Types of decorative elements from the Archaic Period (Muñoz E Chacama 1982: 38).

en tres sectores. En el sector izquierdo de este panel hallamos figuras con formas zoomorfas y antropomorfas y algunas con formas de soles, alcanzando un total de 24 figuras. Esta sectorización del espacio, determinada por dos grandes unidades, como las figuras geométricas lineales cargadas a la derecha del panel, y el resto (soles, antropomorfos y zoomorfos) pintadas en el sector izquierdo del panel, señala la existencia de un ordenamiento específico de las figuras, alcanzando las figuras geométricas una alta representación.

El arte pictórico de La Capilla, hasta el momento el más temprano hallado en la costa de Arica y único en cuanto al tipo de figuras, constituyó un estilo local: presenta una composición organizada de sus diseños, hay un equilibrio y una coherencia en el contexto de las imágenes en los dos paneles donde fueron graficadas. De acuerdo con las fechas radiocarbónicas, este patrón figurativo fue realizado en una época de cambio, en que los pescadores de la costa de Arica se hallaban en un reordenamiento de ideas como consecuencia de las transformaciones generadas en su economía y sociedad.
Al analizar este arte pictórico desde el punto de vista del paisaje, sugerimos dos hipótesis a las cuales podemos vincular estas imágenes rupestres, la primera se relacionaría con la función de delimitar áreas de recursos específicos en relación con pescadores que utilizaban el mismo medio (Bradley et al. 1994). Si pensamos que el sector donde se ubica la cueva es uno de los espacios más productivos para la pesca y recolección en la costa de Arica, estas pinturas se pudieron haber diseñado con el propósito de establecer una identidad que le diera a un grupo de pescadores argumentos para apropiarse de dicho espacio (Vigliani 2006). La segunda hipótesis se podría vincular a la liminaridad o marginalidad. Según Van Gennep (1982) corresponderían a zonas neutras sin apropiación por parte de la comunidad, por lo tanto los ritos de iniciación vinculados con el cambio de vestimenta postulados por Chacama y Muñoz (1991), así como el discurso que podemos abstraer de las pinturas, posiblemente conjugaron una estrategia de los pescadores de apropiarse de dicho espacio. La imaginería rupestre de La Capilla pudo haber simbolizado la relación entre el mundo terrenal y el inframundo representando la conexión común con las profundidades (o el mundo sagrado), que lleva implícita la comunicación con los ancestros y los mitos de origen. La presencia de una inhumación y osamentas humanas de distintas categorías etarias halladas en el estrato 4 podría ser un indicador relacionado con la comunicación con los ancestros (Boyd 1996; Bradley 2002). Los estados liminares según Whitley (1998), además de estar asociados a los dominios terrenales y sagrados, también lo están a cualquier cambio de posición social, de estado o de edad y, por lo tanto, van acompañados de ritos de paso, como pudo haber ocurrido con el rito de iniciación del cambio de vestimenta planteado por Muñoz y Chacama (1982) para la cueva La Capilla.

La ocupación de la cueva refleja la importancia del espacio físico y lo que se generó en el interior de ella como un espacio de múltiples funciones, entre ellas el carácter ritual, ya que se habrían celebrado ceremonias vinculadas a ritos de iniciación. La realización de estos rituales pudo haberse dado considerando que la cueva constituía un monumento donde los pescadores crearon y expresaron su identidad por medio de las imágenes rupestres. Esta identidad pudo ser parte de la complejidad social que se estaba generando en los grupos costeros como consecuencia de los cambios en el plano social y económico que los llevó a manejar determinados espacios productivos bajo el prisma de una nueva concepción ideológica en gestación, en la que el culto a los ancestros habría sido una idea nueva 
en cuanto a concebir el mundo por parte de los pescadores de Arica.

\section{NOTAS}

* Este artículo es resultado del proyecto FondeCyT 1085106.

${ }^{1}$ En la concepción de las poblaciones aborígenes americanas, el color rojo está vinculado con la sangre, es decir, con la vida.

${ }^{2}$ La Tabla 3 se confeccionó sobre la base de los rasgos culturales descritos por Muñoz y Chacama (1982: 11-28).

\section{REFERENCIAS}

Anschuetz, K.; R. WiLShusen \& Ch. ScheiK, 2001. An Archaeology of Landscape: Perspectives and directions. Journal of Archaeological Research 9: 157-211.

Barrett, J.; R. Bradley \& M. GeEn, 1991. Landscape, Monuments and Society. The Prehistory of Carbone Chase. Cambridge: Cambridge University Press.

BitTmann, B. \& J. Munizaga, 1976. The earliest artificial mummification in the world? A study of the Chinchorro complex in northern Chile. Saert \& Folk, Vol. 18, Kobenhaun.

BoyD, C., 1996. Shamanic journey into the otherworld of the archaic chichimec. Latin American Antiquity 7 (2): 152-164.

Bradley, R., 1993. Altering the Earth. The origins of monuments in Britain and continental Europe. Society of Antiquaries of Scotland. Monograph series $\mathrm{N}^{\circ} 8$, Edinburgh.

- 2002. An Archaeology of Natural Places. London: Routledge.

Bradley, R.; F. Criado \& R. Fábregas, 1994. Los petroglifos como forma de apropiación del espacio: Algunos ejemplos gallegos. Trabajos de Prehistoria 51 (2): 159-168, Madrid.

Broda, J., 2001. Ritos mexicas en los cerros de la cuenca: Los sacrificios de niños. En La montaña en el paisaje ritual, J. Broda, S. Iwaniszewski \& A. Montero, Coords., pp. 295-317. México, D. F.: ConaCulta, InaH.

ChaCAma J. \& I. MuÑoz, 1991. La cueva La Capilla: Manifestaciones de arte y símbolos de los pescadores arcaicos de Arica. En Actas del XI Congreso Nacional de Arqueología Chilena, pp. 37-41. Santiago: Museo Nacional de Historia Natural, Sociedad Chilena de Arqueología.

Clarke, D., 1977. Spatial Archaeology. New York: Academic Press.

Criado, F., 1993. Límites y posibilidades de la arqueología del paisaje. Spal 2: 9-55, Sevilla.

— 1999. Del terreno al espacio: planteamientos y perspectivas para la arqueología del paisaje. Santiago de Compostela: Universidad de Santiago de Compostela.

Criado, F.; C. Gianotti \& V. Vásquez, 2000. Túmulos como asentamientos. En Actas do $3^{\circ}$ Congresso de Arquología Peninsular, Neolitización e Megalitismo da Peninsula Ibérica, Vol. III, pp. 289-302. Porto: ADECAP.

Dauelsberg, P., 1974. Excavaciones arqueológicas en Quiani. Chungara 4: 7-38.

— 1985. Faldas del Morro: Fase Cultural Agroalfarera Temprana. Chungara 14: 7-44.

FigueroA, L., 1982. Informe de análisis químico de las pinturas. Documentos de Trabajo 2: 94-96, Arica.

Filgueiras Rey, A. \& T. Rodríguez Fernández, 1994. Túmulos y petroglifos. La construcción de un espacio funerario. Aproximación a sus implicaciones simbólicas. Estudio en la Galicia Centro Oriental: Samos y Sarrias. Espacio, Tiempo y Forma. Prehistoria 7: 211-253.

Florescano, E., 1993. El mito de Quetzalcóalt. México, D. F.: Fondo de Cultura Económica.

Focacci, G., 1974. Excavaciones en Playa Miller 7, Arica (Chile). Chungara 3: 23-74.
Focacci, G. \& S. Chacón, 1989. Excavaciones arqueológicas en los faldeos del Morro de Arica. Sitios Morro $1 / 6$ y $2 / 2$. Chungara 22: $15-62$.

ForCANO, M., 2000. Las pinturas rupestres de potrero de Cháidez, Durango. En Nómades y sedentarios en el norte de México, M. A. Hers, J. L. Mirafuentes, M. Soto \& M. Vallebueno, Eds., pp. 489-510. México, D. F.: Universidad Nacional Autónoma de México.

Geertz, C., 1973. La interpretación de las culturas. Barcelona: Ediciones Gedisa.

Godelier, M., 1984. Lo ideal y lo material. Madrid: Taurus.

Hernando, A., 2002. Arqueología de la Identidad. Madrid: Ediciones Akal.

INGOLD, T., 1986. The Apropiation of Nature. Essays of Human Ecology and Social Relations. Manchester: Manchester University Press.

— 2000. The Perception of the Environment: Essays on Livelihood, Dwelling and Skill, London: Routledge.

Leroi-GOURHAN, A., 1984. Arte y grafismo en la Europa prehistórica. Madrid: Colegio Universitario de Ediciones Istmo.

López Austin, A., 1980. Cuerpo humano e ideología. Las concepciones de los antiguos nahuas. México, D. F.: Universidad Nacional Autónoma de México, Instituto de Investigaciones Antropológicas.

MuÑoz, I., 1982. Las sociedades costeras en el litoral de Arica durante el Período Arcaico Tardío y sus vinculaciones con la costa peruana. Chungara 9: 134-136.

— 1989. El Período Formativo en el Norte Grande (100 AC-500 DC). En Culturas de Chile. Prebistoria. Desde sus orígenes hasta los albores de la Conquista, J. Hidalgo, V. Schiappacasse, H. Niemeyer, C. Aldunate \& I. Solimano, Eds., pp. 107-128. Santiago: Editorial Andrés Bello.

MuÑOZ, I. \& J. ChACAMA, 1982. Investigaciones arqueológicas en las poblaciones precerámicas de la costa de Arica. Documentos de Trabajo 2: 128, Arica.

MuÑoz, I. \& B. ArriazA, 2006. Momificación artificial y patrón de residencia de las poblaciones Chinchorro: Indicadores de una temprana ocupación de cazadores recolectores que habitaron el desierto costero de Atacama. En El hombre temprano en América y sus implicaciones en el poblamiento de la cuenca de México, J. Jiménez, S. González, J. Pompa \& F. Ortiz, Coords., pp. 107-144. México, D. F.: Instituto Nacional de Antropología e Historia.

Muñoz, J., 1973. Geología de Chile. Santiago: Editorial Andrés Bello.

Murra, J., 1975. Formaciones económicas y políticas del mundo andino. Lima: Instituto de Estudios Peruanos.

Niemeyer, H., 1972. Las pinturas rupestres de la sierra de Arica. Santiago: Editorial Jerónimo de Bibar.

Renfrew, C., 1983. The Megaliths Monuments of Western Europe. London: Thames \& Hudson.

Rivera, M.; P. Soto, L. UlloA \& D. Kushner, 1974. Aspecto sobre el desarrollo tecnológico en el proceso de agriculturación en el norte prehispánico, especialmente Arica (Chile). Chungara 3: 79-107.

Riviere, G., 1982. Dualismo y cuatripartición en Carangas. Revista del Museo Nacional de Etnografía y Folklore 1 (1-2): 67-121, La Paz.

SANTORo, C., 1980. Fase Azapa, transición del Arcaico al desarrollo agrario inicial en los valles bajos de Arica. Chungara 6: 46-56. 1980. Estratigrafía y secuencia cultural funeraria: Fase Azapa, Alto Ramírez y Tiwanaku (Arica, Chile). Chungara 6: 24-45.

SHENNAN, S., 1994. Introduction: Archaeological approaches to cultural identity. En Archaeological Approaches to Cultural Identity, S. Shennan, Ed., pp. 1-32. London: Routledge.

VAn Gennep, A., 1982. Los ritos de paso. Madrid: Taurus.

VICENT, J. M., 1990. El Neolitic, transformacions social i econòmiques. En El Canvi Cultural a la Prebistoria, J. Anfruns \& P. Llobet, Eds., pp. 241-293. Barcelona: Editorial Columna.

Vigliani, S., 2006. Diversidad e identidad en las sociedades cazadoras recolectoras. Tesis para optar al grado de Maestría en Arqueología. Escuela Nacional de Antropología e Historia, México, D. F.

Whitley, D., 1998. Finding rain in the desert: Landscape, gender and far western North American rock-art. En The Archaeology 
of Rock Art, Ch. Chippindale \& P. Tacon, Eds., pp. 11-29. Cambridge: Cambridge University Press.

Williams, H., 1998. Monuments and the past in early Anglo-Saxon England. World Archaeology 1: 90-108.
ZEDEÑO, N., 1997. Landscapes, land use, and the history of territory formation: An example from the Puebloan Southwest. Journal of Archaeological Method and Theory 4 (1): 67-103. 